\title{
Perspectives on trading cost and availability for corrective maintenance at the equipment type level
}

\author{
John Ahmet Erkoyuncu* ${ }^{a}$, Samir Khan ${ }^{c}$, Alexandre López Eiroa ${ }^{a}$, Nigel \\ Butler $^{\mathrm{b}}$, Keith Rushton ${ }^{\mathrm{b}}$, Simon Brocklebank ${ }^{\mathrm{b}}$ \\ ${ }^{a}$ Manufacturing Department, Cranfield University, Cranfield, Bedfordshire, MK430AL, UK. \\ ${ }^{b}$ EquipmentSupport Continuous Improvement Team, Ministry of Defence, Abbey Wood, Bristol, B34 \\ 8JH, UK. \\ 'Department of Aeronautics and Astronautics, University of Tokyo, Tokyo 113-8654, Japan \\ *Corresponding author, email: j.a.erkoyuncu@cranfield.ac.uk
}

\begin{abstract}
Characterising maintenance costs has always been challenging due to a lack of accurate prior cost data and the uncertainties around equipment usage and reliability. Since preventive maintenance does not completely prevent corrective repairs in demanding environments, any unscheduled maintenance can have a large impact on the overall maintenance costs. This introduces the requirement to set up support contracts with minimum baseline solutions that warrant the target demand within certain costs and risks. This article investigates a process that has been developed to estimate performance based support contract costs attributed to corrective maintenance. These can play a dominant role in the through-life support of high values assets. The case context for the paper is the UK Ministry of Defence. The developed approach allows benchmarking support contract solutions, enabling efficient planning decisions. Emphasis is placed on learning from feedback, testing and validating current methodologies for estimating corrective maintenance costs and availability at the Equipment Type level. These are interacting sub-equipment's that have unique availability requirements and hence have a much larger impact on the capital maintenance expenditure. The presented case studies demonstrate the applicability of the approach towards adequate savings and improved availability estimates
\end{abstract}

Keywords: Corrective Maintenance, Maintenance Float Systems, Finite Source Queuing Theory, Availability at Risk, Maintenance Cost

\section{Introduction}

The evolution of business services are strongly dependent on the correct functioning of modern technical systems. These systems warrant operational performance and efficiency which dictates the amount of maintenance required; a consequence of the design and failure modes encountered during operation (Ahn and Kim, 2011). Maintenance (both preventive and corrective) therefore has an impact on both cost and operational availability.

Two aligned fields that deserve mention at this point are Product Service Systems (PSS) and Health Management. PSS (Qu et al, 2016), which is also linked to servitization (Baines et al, 
2009), stemmed from some OEMs transforming their business model from selling a product to selling a service. In the product scenario, income is determined from the original sale and future income is dependent on the sale of spare parts. In the service scenario, a maintenance contract is sold at the same time as the asset and hence a steady monthly income is derived, in return for effective maintenance; the OEM has become the maintainer and captured more of the value chain. Though, with the large number of equipment to maintain, OEMs and the customer need to find effective ways to handle the sheer amount of data that is available. For strategic maintenance analysis, this promotes the need to move away from component level focus to the Equipment Type (ET). ET is any set of subequipment, which operate together that have a unique demand profile. It can belong to various platforms, e.g. tanks or aircraft, or even role equipment that is not permanently fitted, e.g. missiles. ETs are interacting sub-equipment's, which have unique availability requirements and hence have a much larger impact on the capital maintenance expenditure. On the other hand, health monitoring arose to better inform the OEMs of the behaviour of their assets in service (Baines and Lightfoot, 2014). It provides data from sensors on the asset and processes it, via diagnostic or prognostic algorithms, into actionable information. Figure 1 shows a generic operating environment that can be found across the engineering sectors. Within the figure, the OEM (Original Equipment Manufacturer) supplies an asset to an operator who is going to use it as part of a business to make a profit. The operator needs the equipment to be regularly maintained and the maintainer will have access to the OEM's supply chain for spare parts. This is all done with respect to certain standards, certification and policies. It demonstrates some of the interactive complexities that can arise during a service, which must be investigated to manage system availability and reduce surplus costs (Erkoyuncu et al, 2015). Accordingly, the figure also demonstrates that the ET level involves e.g. a radar, engine, and sonar; as compared to the aircraft level, system level or component level. This means that an ET could be present in multiple equipment's and may vary over time based on the customer demand profile.

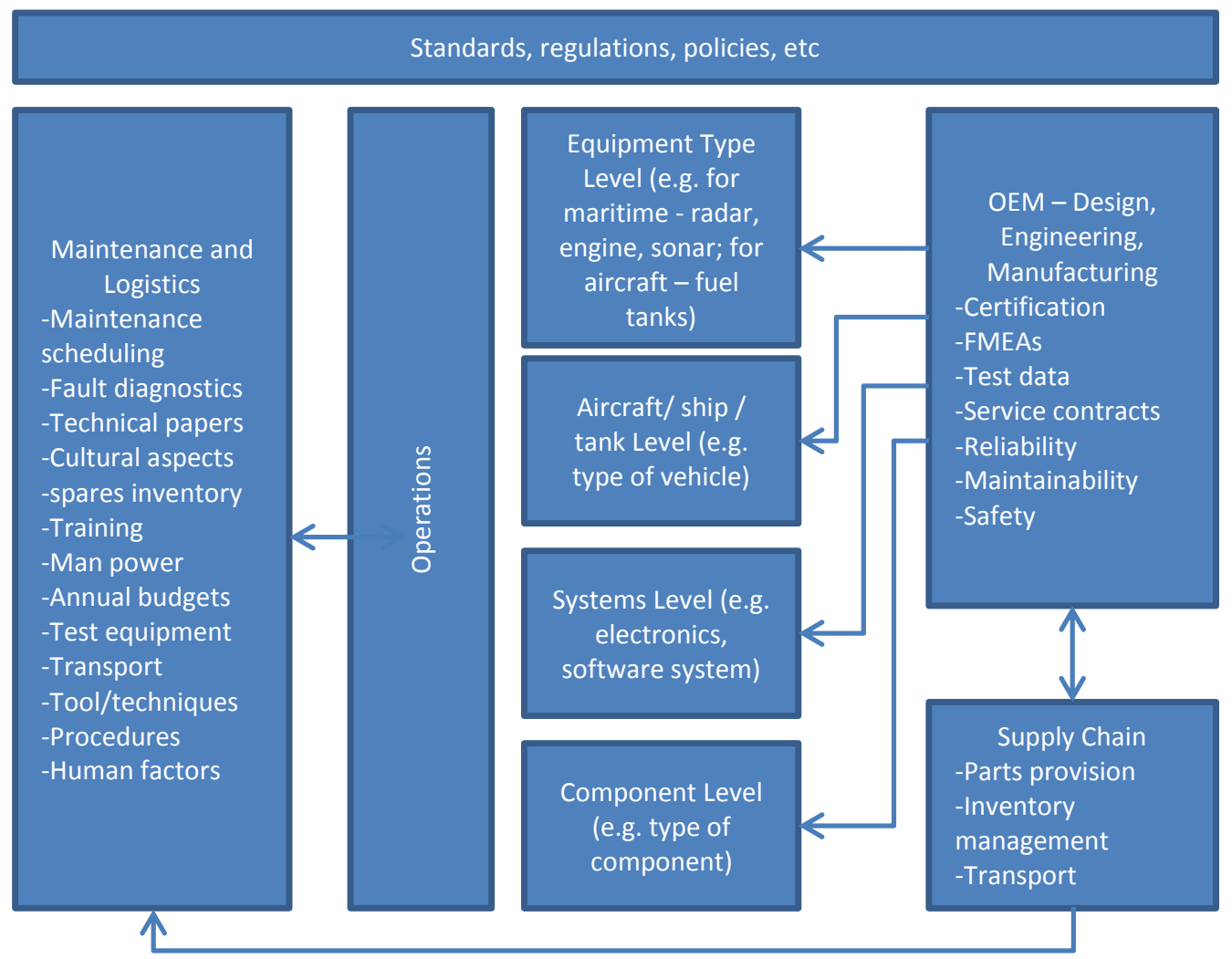

Figure 1. The operating environment 
Within the overall operating environment, the effectiveness of each constituent system becomes important. System effectiveness is the ability for a system to achieve its required operational capability, from either a cost or availability viewpoint. This is in order to embrace the constituent parts of availability - namely reliability, maintainability and logistics support (Khan et al 2015). The primary aim over here is to define, deliver and evaluate how an optimal system performance (e.g. availability) can be achieved at affordable through-life costs. Having an integrated (and iterative) setup can help develop a comprehensive support strategy to optimize functional support, leverage existing resources, and quantify life cycle costs (demand for logistics). Such an integrated logistics support is widely used in commercial services organisations (Keeffe and Ormsby, 2015). This is used as a business case for judging an optimum balance between the time invested in performing certain actions such as Preventive Maintenance (PM) and Corrective Maintenance (CM). In this context, the UK Ministry of Defence (MoD) is developing several approaches to manage its high value equipment/assets; this is indicative of a growing awareness of the problem - rooted in the need to:

- Improve the availability of equipment and vehicles (Erkoyuncu et al, 2014),

- Reduce the turn-around times for aircraft (Ayeni et al, 2016),

- Provide an efficient and cost effective maintenance service (Baines and Lightfoot, 2014),

- Mitigate against the cost impact of warranty claims (Khan et al, 2014a).

There are three driving forces at work here. The first relates to the collapse of the world economy since 2008. For example, in aerospace the economic downturn has led to rising fuel costs and increasing taxes. Cost savings have therefore had to be found and tackling wasteful and inefficient maintenance has become a prime target for cost reduction. Likewise, government spending cuts, particularly evident within the UK, have significantly downsized both armed forces personnel and the purchasing of spare parts. This forces maintenance activities to modernize and become smarter. The second driving force is the increase in contracting for availability. Here maintenance and repair is the responsibility of a $3^{\text {rd }}$ party who guarantees the customer that they will have a specific availability for their equipment or vehicle. Maintenance plays an important role in contracting for availability, as the commercial contracts needs to define who is responsible for these costs: re-test, recertification, etc. The final driving factor is down to the increased complexity of engineering systems coupled with a reduction in the skill-set of the relevant maintenance personnel.

So the availability of equipment is an essential driver. Within the defence sector, availability is influenced by several factors which include logistics, equipment, personnel, information and facilities (Hastings, 2015). The authors of this paper are studying these issues by focusing on selected subsystems - that are referred to, within the UK MOD and in this paper, as Equipment Type (ET).

Each ET produces available days (Equipment Available Days or EADs) during a certain planning period. The process is managed by the Equipment Support Continuous Improvement Team (ESCIT) of the UK MoD who estimate the resources required for maintenance to meet an availability target for an equipment type at affordable levels. Therefore, MoD ESCIT's requirements are:

- To develop an analytical model that is simpler and faster to run,

- To establish a budgetary baseline, generally for short term planning (e.g. one year) and with the possibility of ongoing inputs updates and recalculation, 
- To obtain a benchmarking criterion even when data maturity is not enough to run more complicated models: modelling at equipment type level requires simplified high level inputs.

\subsection{Contributions and importance of this work}

The aim of this article is threefold: (1) to develop a methodology to estimate the cost of maintenance resources required to achieve a certain availability level, (2) to assess the maturity level and confidence levels on the prediction availability, and (3) to validate the analysis and result.

Keeping within the research scope, careful thought was placed on selecting the title of the article; which suggests that the paper presents "perspectives". The aim is to indicate that the authors have adopted a pragmatic approach to the problem rather than providing a comprehensive review. Fortunately, there are other much detailed literature publications that have carried out rigorous reviews on related topic (e.g., see Gao et al (2015), Schwabacher and Goebel (2007), Travé-Massuyès (2014) and Zalewski and Wojcik (2014)), however, to the best of the authors' knowledge, there is only limited published work that discusses performance support contracts at the equipment type level. None-the-less, this article should still be of general interest to commercial personnel and researchers who are working in the areas of maintenance design and performance management. The paper also presents some challenges with current MoD procedures, and hence the efforts are mainly focused upon the military environment; however, other disciplines should be able to find the contents of this paper appropriate. Finally, the contributions in the paper can be summarised as follows:

- This is the first paper to define a process to trade-off cost and availability from CM actions,

- This is the first paper to identify the list of resources required at the Equipment Type level to deliver maintenance,

- Development of a methodology which can be used as a decision support to estimate CM costs,

The proposed study has its merits. It addresses a critical need by presenting a cost estimation technique for availability contracts. The solution can also emulate the costs at different levels of granularity i.e. across organisation. But more importantly, the paper has managerial implications at the ET level:

- For system manufacturers, it offers an opportunity to develop contracts to the system integrators that take in to account the CM costs and availability,

- For system integrators, it provides an approach to estimate the support costs and availability so that bid proposals with higher confidence can be put forward to the system operators,

- For system operators, a systematic process is offered to estimate costs and availability across the supply chain. 


\subsection{Organisation of the paper}

The paper is structured as follows: Section 2 discusses the literature review. The methodology, adopted by the authors to carry out this research work is detailed in Section 3. This is followed by the development of a cost estimation methodology in Section 4. Section 5 presents the implementation of the concept, and discusses its implications to estimate the $\mathrm{CM}$. This is supported by a validation of the methodology from the MoD team. Finally, Section 6 highlights the conclusions and the future work from the research.

\section{Literature review}

\subsection{Maintenance Practice}

Maintenance programs for key systems such as avionics, engines and landing gear, are made up of several types of maintenance policies such as preventive, corrective, and on-condition maintenance. Preventive maintenance is the process of performing specific inspections, tests, measurements, adjustments or part replacements, specifically aimed at preventing failures. These preventive actions are taken at pre-determined intervals based upon a time interval such as hours or days, or the number of operations, such as the number of landings in the case of landing gear. Corrective maintenance follows the principle of "run to failure" where the effect is not necessarily serious or disruptive to the mission. The CM action will consist of replacing a failed system, subsystem or component to ensure that full, fault-free, operating condition is restored. Of course, $\mathrm{CM}$ also covers those unexpected failures which can be serious or disrupt the mission. On-condition maintenance can support PM where components are replaced based upon observation and test results. Each of these activities is further supported by $\mathrm{CM}$ which will only be conducted in response to discrepancies or failures during operation. All these strategies provide for redesign if necessary to solve fleetwide issues and will result from a growing amount of evidence based upon the actual usage of the system. The process should ensure that engineering modifications are made in order to address safety or reliability issues which were not anticipated in the original design. Ideally, information from maintenance activity, performed by all users of the system, should feed back into any redesign activity; however, this often does not happen.

Therefore, optimizing maintenance becomes an essential part of any change in maintenance strategy for operators and the service solutions that MRO suppliers can provide. This helps in reducing the levels of $\mathrm{CM}$ and $\mathrm{PM}$ and hence optimizes maintenance effectiveness on aircraft fleets. The changing face of the aviation industry requires that maintenance management becomes increasingly tailored towards individual customers' needs with costeffective solutions being found, offering compromises between customer involvement and the level of commitment required from the providers. Figure 2 shows a matrix with different maintenance solutions and the level of commitment and partnerships required by the operators and MRO providers for a variety of maintenance contract types. It illustrates the relationship between the level of MRO Support that is needed against the involvement from aircraft operators. Traditional maintenance evolution is depicted along the diagonal from bottom right to top left. Time and materials, equating to "fix when broke", involves low (reactive) participation from both Operator and MRO. Predictive maintenance significantly improves this state by being more proactive, and gets both parties more involved. CBM (top left) represents, for a number of companies, a highly desirable business model for proactive maintenance, but demands high commitment from both sides. Other possibilities are also shown in the figure, including Through Life Support. This is where an MRO contracts to 
maintain an asset through its life, taking total commitment from the MRO and low to medium involvement from the Operator.

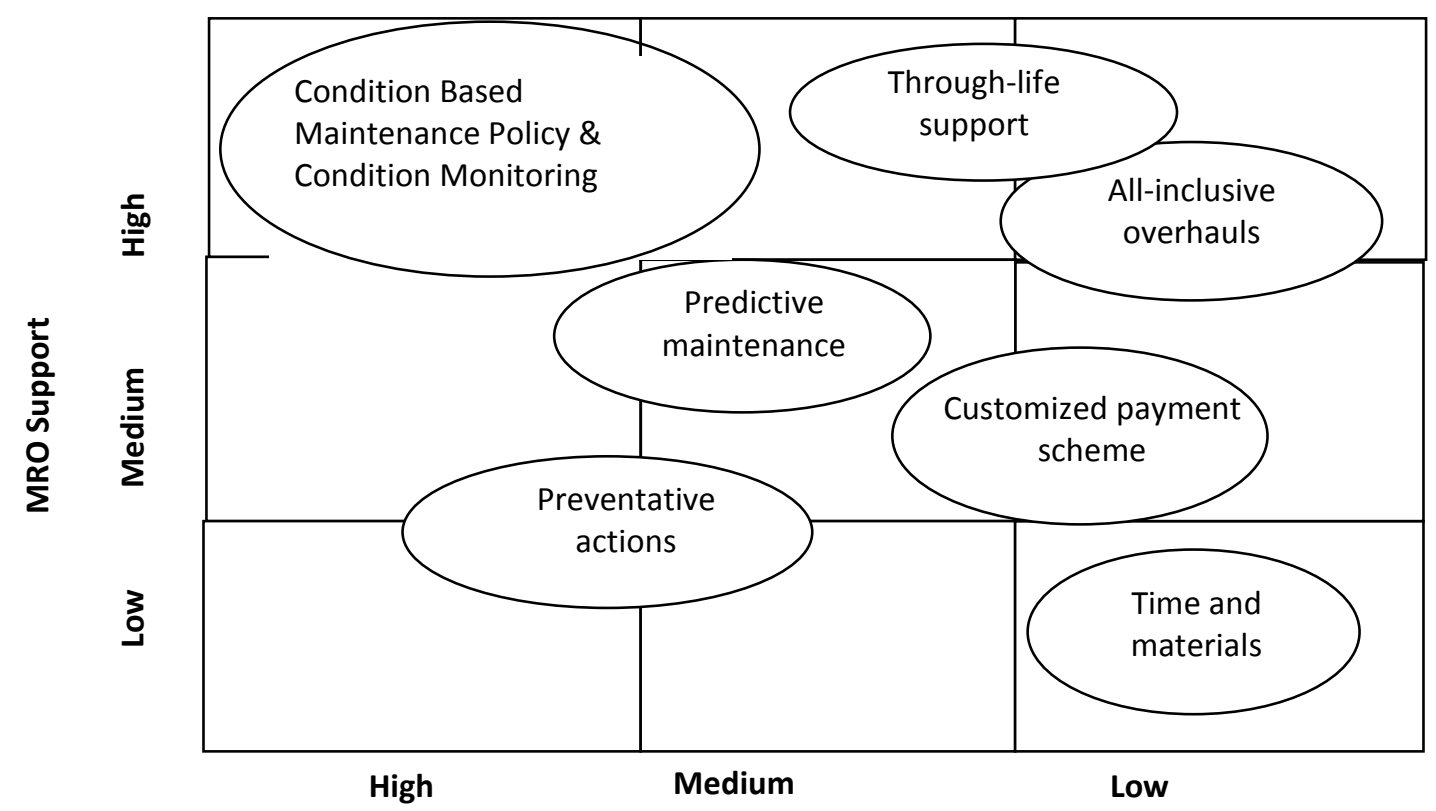

Aircraft Operator Involvement

Figure 2. MRO Support vs Operator involvement for maintenance contract types

\subsubsection{Availability}

Availability is the key requirement of any complex engineering related service and support provider. The delivery of a capability or an output and the relevant equipment must be available when needed. No matter how capable an asset is, and how much potential it has, if it does not work when needed, it is virtually useless. According to NATO ARMP-4 (2001), "availability is the probability that the system or equipment used under stated conditions will be in an operable and committable state at any given time".

The definition highlights at "any given time" but this has to be tied in with the phrase "committable" indicating the period of standby before the required mission starts. The equipment is assumed to be in full working order and ready for the mission and thus is available for use at a constant level going forward. However, once in use, the availability level will fluctuate. Consequently availability metrics are usually measured as functions of time and in their simplest form are measured as a ratio of available time to total time. The available time is the "uptime" and the remaining time is therefore "downtime" or the time the equipment is unavailable, as illustrated in Equation 1. This equation does not separate the time spent on PM or CM, as it considers the total time. Uptime can be viewed as reliability and downtime - as time to repair. If downtime is considered as the time to repair, and the uptime as the time it is working between failures, it is possible to convert uptime and downtime to MTBF and MTTR (Khan et al, 2015). Consequently: 


$$
A=\frac{\text { Uptime }}{\text { Total Time }}=\frac{\text { Uptime }}{\text { Uptime }+ \text { Downtime }}=\frac{M T B F}{M T B F+M T T R}
$$

[Equation 1]

In an ideal situation, there is no consideration of standby periods or of logistic and administrative delays. Thus, issues that can cause delays - including time to complete paperwork, time waiting for manpower, tools, test equipment and of course time waiting for spares - must be considered. Whilst the operator is really interested in operational availability, it must be noted that reliability, maintainability, supportability and the other constituent parts of availability are crucial and must be established and optimized for the economic and environmental success of systems. When there is no proper PM routine established, CM accounts for majority of the total maintenance costs (Erkoyuncu et al 2015).

In many businesses, the availability of a system is typically only measured as a factor of its uptime and downtime without really assessing or understanding its actual reliability, but it is clear that once the design is final, improving either reliability or maintainability is very difficult (Khan et al, 2014a). But often problems do not get identified until the whole system is built and users who are involved in trials and tests under representative conditions; have provided their feedback (Bano and Zowghi, 2015). At this stage, however, it is too late to make design changes purely for availability improvements, hence the problem of estimating the cost trade-off represented in preventive and corrective actions does not manifest itself until the equipment enters operational service. Consequently, the influence of $\mathrm{CM}$ (or downtime) does not become clear until it happens, perhaps well into the life cycle of the system with all the attendant frustration and loss of availability. It is important to note as well that administrative delays and costs are largely ignored at the design stage; yet it is mainly administrative delay that drive the level of operational availability and which has a greater effect usually than CM or PM (Khan 2014a, Khan 2014b).

\subsubsection{Maintenance cost estimation}

Datta and Roy (2010) have reviewed the main cost modelling techniques for availability contracts: bottom-up, top-down and hybrid costing; what-if scenario analysis, end-to-end estimates, analogy estimates and joint cost models. Thus, the overall problem consists in estimating how the expense on a certain level of resources is going to impact availability. Below, the main two approaches to address this problem are covered: the so called mean based or analytical solution and the use of simulation techniques, such as discrete event simulation (DES). There exist some attempts to analytically model the problem of availability and cost estimates (Rahman and Chattopadhyay, 2008). However, this approach is purely theoretical and relies on many variables very difficult to know in reality. On the other hand, as mentioned before, there exists a significant amount of simulation research aimed to model maintenance in the defence sector. Some representative examples are outlined below.

Bender et al. (2009b) assessed a queue server maintenance model through DES at system level. They studied how microscopic scale uncertainties in the inputs (e.g. arrival times) amplify the effects on the long term fleet availability. In addition, they determined the causes for those magnification effects (Bender et al., 2009a), being the main one the decay phenomena (.i.e. the failure rate grows during equipment life due to aging). Moreover, they added the evaluation of how the spares inventory management strategies affect the result (Sherman et al., 2011). Hagmark and Virtanen (2007) performed a comprehensive simulation 
approach that integrates the result at the top identity through multiple states of the subcomponents and their interrelation using logic gates. Madu et al. (1995) modelled a maintenance float system and provided a decision support tool to assess how availability can be improved or resources diminished (e.g. the effects of improving reliability or maintainers skills). Similarly, Peito et al. (2013) built a highly flexible DES maintenance float system model to study the effect of the main factors on performance indicators (cost and availability) in a production environment.

In addition, Upadhya and Srinivasan (2003) studied aircraft availability estimation. As novelties, the model included the consideration of multiple failures (opposite to the binary "failed" or "working condition") for each component to integrate the result for the equipment as a whole; and failures were separately modelled as due to battle damage and unreliability. The outcome showed the effect of logistic delays on the availability during battles (short term planning). They also analysed the results when considering different missions types and extended it to peace situations (Upadhya and Srinivasan, 2005; Upadhya and Srinivasan, 2012). Orsagh et al. (2003) undertook a very similar approach, considering battle damage and unreliability failures to simulate mission conditions, combined with the analysis at component level. The model is represented in Figure 3.

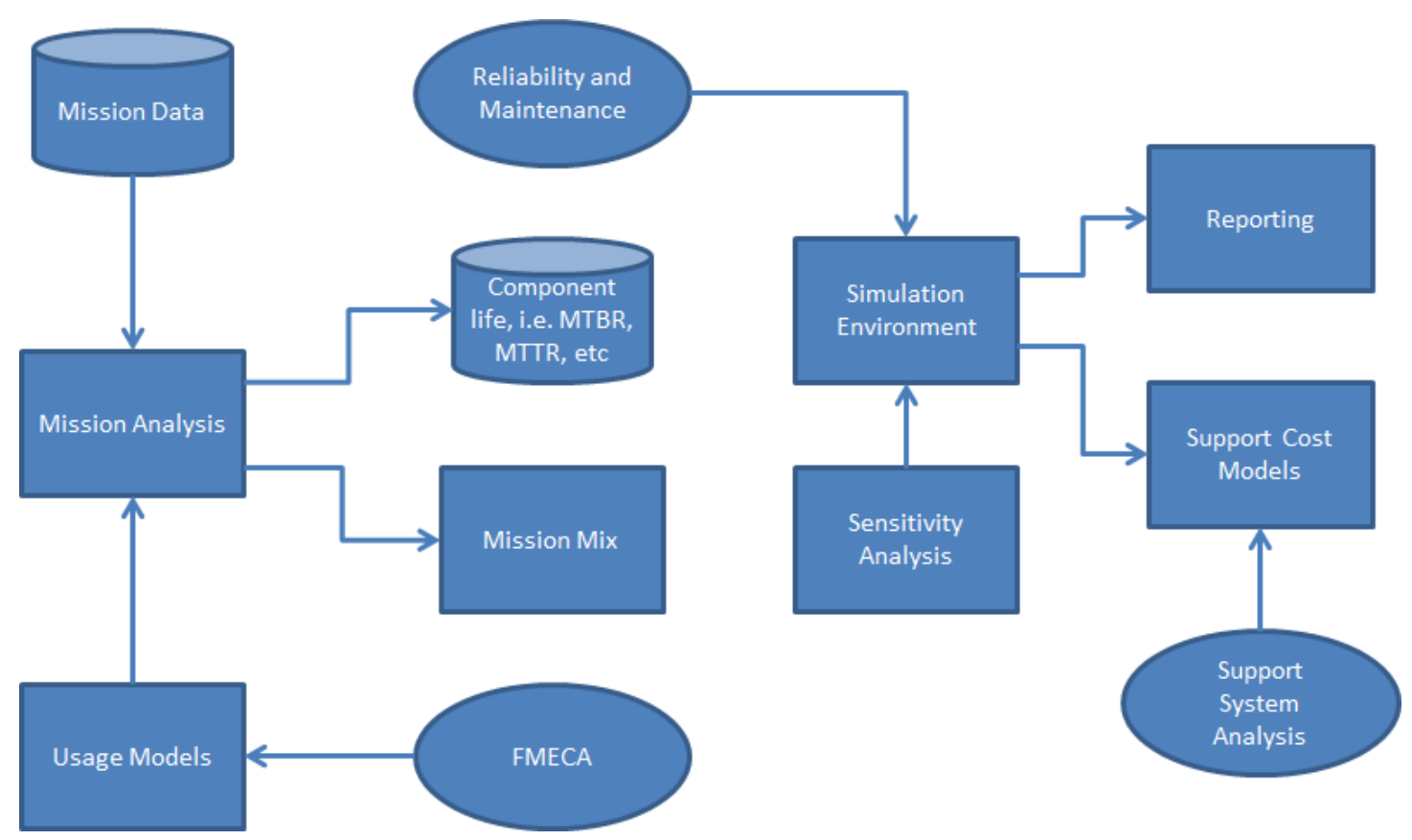

Figure 3. Block diagram of mission-based support cost modelling system. Source: (Orsagh et al., 2003)

Regarding other simulation methods, Monnin et al. (2007) used simulation based on Stochastic Activity Networks (which are a type of Petri Nets) to analyse how regeneration (i.e. on-line maintenance) contributes to availability. They modelled battle damage and unreliability failures as well, but the problem was not analysed from a costing perspective.

Moreover, Simeu-Abazi et al. (2014) simulated a maintenance workshop following a queuing network-based methodology to evaluate the required service points and spares required.

Focusing on the spares management, the impact of stock levels on availability has not been extensively studied (Ghodrati et al., 2010), and they mean an important part of the maintenance costs and can significantly affect availability. Some specific research has been carried out (Ghodrati, 2005; Sheikh et al., 2000), but the latest example is the study 
developed by Ghodrati et al. (2010), which incorporates the influence of usage conditions to failure prediction and the influence of stock levels on availability.

All of the presented simulation models provide a lot of flexibility when characterising the maintenance system and its working conditions. Moreover, all these models are really useful to study and assess the influence of the inputs on the result or the system behaviour for a given set of conditions. Even though mean based solutions lack the heuristic characteristic of maintenance processes (due to all the uncertainties present), ESCIT approach compensates this by associating a level of risk to the solution.

\subsection{Research Gaps}

From the above review, a few research gaps have been identified:

- There is a need to establish a budgetary baseline, generally for short term planning and with the possibility of ongoing inputs regarding updates and recalculation. This is because there are unseen maintenance related tasks which are not accounted for during the design stage.

- Currently, majority of the models focus on component level analysis, which requires detailed failure records as well as complex and time-intensive calculation procedures. There are no approaches that account for incorporating Equipment Type level analysis.

- Maintenance is a complex term, comprising a variety of actions on any kind of technical systems, which deteriorate differently and follow random behaviours. There is no unique universal model that covers all maintenance aspects. In spite of the multitude of models published in papers so far, the majority can be applied only to specific problems rather than taking a holistic perspective.

- Most of the research conducted in maintenance optimisation processes mainly considers the procession environment, which is often different from the military context.

- Trade-off between effort to apply the maintenance procedure and savings gained is very often highlighted as a challenge. It happens that the potential benefits of a better decision making process are hardly compared to the time and effort invested in methodology development and data gathering.

- Not many validated methodologies have appeared in scientific literature.

This paper primarily addresses the first two listed gaps. The developed process allows to trade-off cost and availability within ET context.

\section{Research Methodology and Identifying the Current Practice}

This study has actively been involved with maintenance engineers from defence backgrounds. The paper adopts a similar research methodology used in Erkoyuncu et al (2016) i.e. the Soft Systems Methodology (SSM) proposed by Checkland (1981). It is used to capture the current practice and challenges in planning maintenance activities and to build a new framework to be able conduct the trade-off for resources required for $\mathrm{CM}$ to understand the impact on cost and availability at the ET level. The SSM was adopted due to its flexible approach to elicit information from the real world industrial context of maintenance planning and to improve practices with optimising cost and availability for complex engineering products. The research participants initially involved three engineers that illustrated the significance of the maintenance challenge with respect to cost and equipment availability and how the maintenance planning was conducted. These preinterviews were used to develop a survey/questionnaire to collect relevant information 
about CM plans. This approach was adopted to be relevant for two reasons: 1) it tackles soft problems where there is a lack of definition of the investigated concept, 2) it offers to present a view of what could exist in the real world. For these reasons, the SSM approach was adopted against other methods, such as structured systems analysis, business process modelling and value stream.

In the process of conducting research, the authors have utilised a multi-method design involving the use of: document analysis, workshops and semi-structured interviews. These methods (a workshop and 5 sets of semi-structured interviews lasting on average two hours) were used to gather and analyse data from 6 key participants from the UK MoD ${ }^{1}$ ESCIT team with industrial experiences ranging from 8- 35 years, as described in Table 1. The type of data elicitation technique was influenced by the industrial context and nature of the study. The key informants were selected based on their extensive knowledge and willingness to share their knowledge and skills for this research. These individuals were considered to have in-depth knowledge in maintenance planning. The process that was adopted for the methodology is covered in Figure 4.

Table 1. List of participants

\begin{tabular}{|c|c|c|c|c|}
\hline$\#$ & $\begin{array}{c}\text { Position of } \\
\text { attendee }\end{array}$ & Background & Experience & Contributions \\
\hline $\begin{array}{l}\text { Participant } \\
1^{*}\end{array}$ & $\begin{array}{l}\text { ESCIT Team } \\
\text { Leader }\end{array}$ & $\begin{array}{l}\text { Reliability } \\
\text { engineering }\end{array}$ & 34 years & $\begin{array}{l}\text { Problem Overview, } \\
\text { Requirements Definition, } \\
\text { Scope Clarification and } \\
\text { Process Validation }\end{array}$ \\
\hline $\begin{array}{l}\text { Participant } \\
2^{*}\end{array}$ & $\begin{array}{l}\text { Programme } \\
\text { Leader }\end{array}$ & $\begin{array}{l}\text { Service and } \\
\text { support }\end{array}$ & 28 years & $\begin{array}{l}\text { Process Development } \\
\text { phase, Constant, Process } \\
\text { Updates, each } \\
\text { development stage } \\
\text { approval, and Process } \\
\text { Validation }\end{array}$ \\
\hline $\begin{array}{l}\text { Participant } \\
3^{*}\end{array}$ & $\begin{array}{l}\text { Support } \\
\text { Solution } \\
\text { Specialist }\end{array}$ & $\begin{array}{l}\text { Reliability } \\
\text { engineering }\end{array}$ & 22 years & $\begin{array}{l}\text { Process Development } \\
\text { phase, Process Updates } \\
\text { and Process Validation }\end{array}$ \\
\hline Participant 4 & $\begin{array}{l}\text { Project } \\
\text { Manager }\end{array}$ & $\begin{array}{l}\text { Operational } \\
\text { performance } \\
\text { engineer } \\
\end{array}$ & 12 years & $\begin{array}{l}\text { Process Development } \\
\text { phase }\end{array}$ \\
\hline Participant 5 & ILS Manager & $\begin{array}{l}\text { Maintenance } \\
\text { engineering }\end{array}$ & 8 years & Process validation \\
\hline Participant 6 & $\begin{array}{l}\text { Maintenance } \\
\text { Technician } \\
\text { Lead } \\
\end{array}$ & $\begin{array}{l}\text { Maintenance } \\
\text { engineer }\end{array}$ & 15 years & Process validation \\
\hline
\end{tabular}

* participants took part in the pre-data collection process and validation process

During Phase 1 (stages 1 and 2) of the research project, an initial list of cost and availability drivers were developed. In Phase 2 (stages 3, 4, 5 and 6), the developed list was further refined, additionally the process for $\mathrm{CM}$ trade-off was developed; leading to the finalised

\footnotetext{
${ }^{1}$ For confidentiality purposes and at the request of participating individuals, anonymised descriptions of informants are provided to avoid making the individuals easily identifiable at least to those familiar with the defence or naval industry.
} 
process and list of cost and availability drivers from CM activities. Phase 3 (stage 7) focused on developing an optimisation approach to estimate the cost and availability for $\mathrm{CM}$ plans to define the exact amount and proportion of $\mathrm{CM}$ activities at the equipment type level.

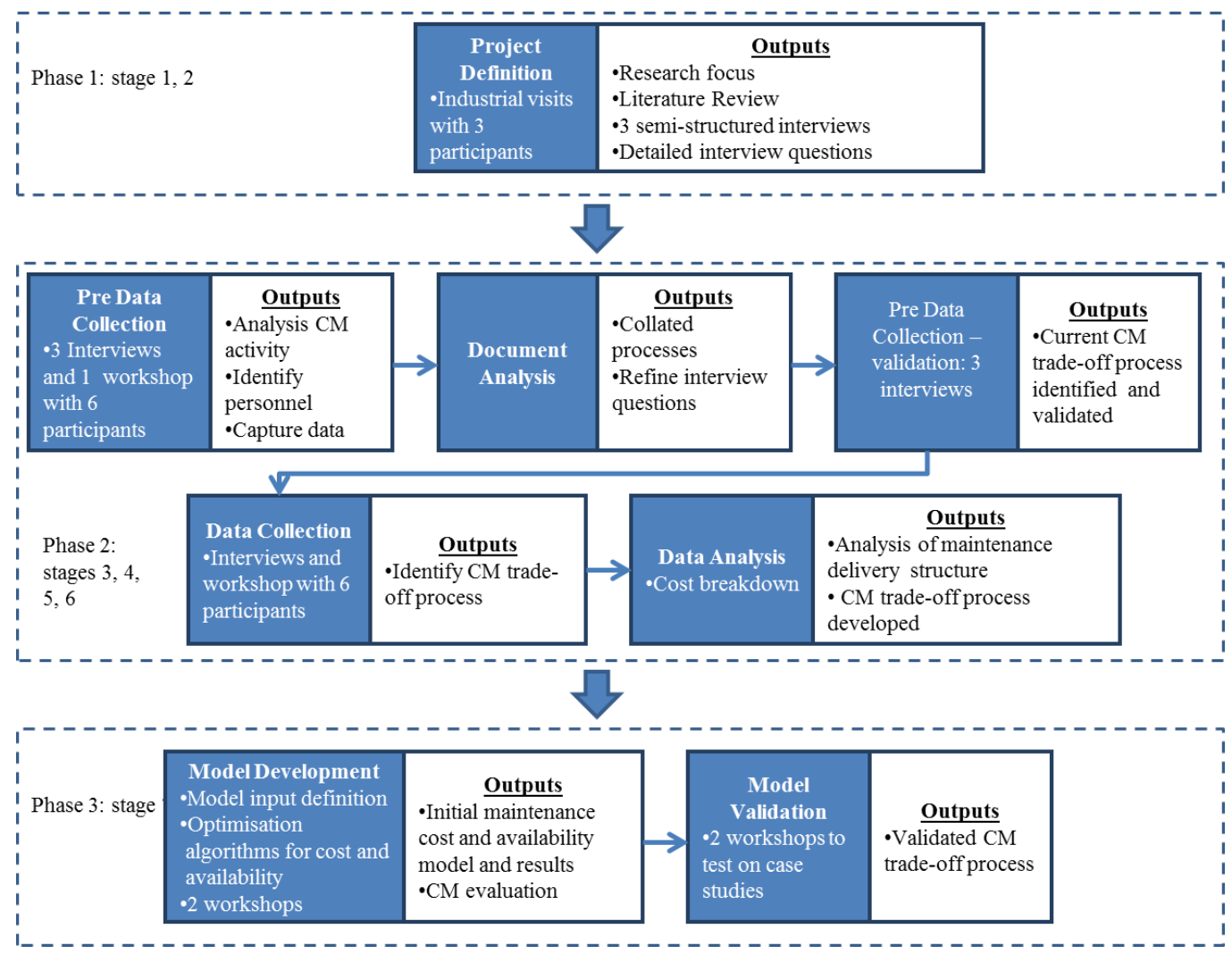

Figure 4. The adopted research methodology for data collection and model development

\subsection{Familiarisation of corrective maintenance plans (Soft Systems Methodology stages 1 and 2)}

This involved a comprehensive review of related literature in order to understand the impact of the CM activities on the overall maintenance plans in terms of cost and availability impact and the state-of-the-art in academic related research. This consisted of topics such as the current maintenance approaches, key factors driving $\mathrm{CM}$, cost of $\mathrm{CM}$, link between equipment availability and maintenance, processes and methodologies which are used in practice or have been proposed for the optimisation of cost and availability outcomes from $\mathrm{CM}$ activities. Subsequent to the literature review, a series of industrial interviews ( $3 \mathrm{semi}$ structured interviews with Participant 1-3, each lasting 2 hours) were carried out with the UK MoD ESCIT team. In alignment with the targets set out for this research, the focal point of the industrial data collation was in line with the first three stages of the Soft Systems Methodology (Checkland, 1989).

The goal of the industrial engagement was to address:

- How are maintenance plans developed?

- What are the challenges of trading off cost and availability for $\mathrm{CM}$ activities?

- How can the cost of $\mathrm{CM}$ be estimated? 
- How can the equipment availability be estimated in light of $\mathrm{CM}$ activities?

The literature review helped understand the state of maintenance research around CM processes at ET levels.

The literature review aimed to provide insights for industrial practitioners and academic researchers on the major trends, significant works, and future directions on maintenance optimisation. Along these lines a detailed literature review was conducted. The literature search was limited to the timeframe between 1990 and 2016. An extensive review of literature and scientific papers on maintenance optimisation models were performed using keyword search (maintenance, trade-off, CM, PM, cost and availability) in the major databases. In this process a range of journal and conference articles around maintenance optimisation was reviewed. A variety of electronic databases contributed to the findings including: Scopus, Emerald insight, Science Direct, IEEE Xplorer, and IET Digital Library. One of the key findings of the literature review was the lack of breakdown of cost and availability drivers in maintenance optimisation, also there was a lack of information provide at the equipment type level, where there was a breadth of content at the component level. For the semi-structured interviews (three in total with Participants 1, 2 and 3), experts commented on why it is growing in importance to measure the impact of $\mathrm{CM}$ activities on cost and availability. The interviews also put an emphasis on what are the cost and availability drivers and how these $s$ can be modelled to minimise the effort required for $\mathrm{CM}$.

The results from the interviews and literature review lead to the development of a further detailed questionnaire for Phase 2 of the research methodology. The questions aimed to validate the findings across a broader set of participants and in a more detailed sense. Further details on the survey are provided in Section 5.

\subsection{Development of an initial list of cost and availability drivers (Soft Systems Methodology stages 3 and 4)}

An essential part of the research effort has been applied to gain cost and availability knowledge for CM practices. The second phase of the research methodology focused on reviewing the current practice through documents obtained from ESCIT and six face-to-face interviews each lasting two hours (with Participant 1, 2, 5 and 6) and one workshop (including Participant 3, 4 and 6), which also lasted two hours. In this process, the industrial engagement was managed iteratively to elicit a list of potential cost and availability drivers based on three challenging projects that the participants delivered within their context. The interviews also explored the current processes for managing maintenance and estimating the costs and availability of $\mathrm{CM}$ activities. Subsequently the workshop aimed to validate the list of cost and availability drivers and processes for maintenance planning. This approach has led to the basic understanding of how cost and availability is considered for CM activities.

The support planning framework comprises a series of processes to calculate maintenance costs:

- Levers: they are a set of tools aimed at calculating the cost of $\mathrm{CM}$ requirements (e.g. maintainers and spares) to deliver the required availability at a certain risk and cost.

- Combi-lever: is a tool that aggregates the results given by the individual levers, providing an overall figure for cost at a certain risk level for an ET. 
- Trade-off analysis between PM and CM maintenance): study of the effect of scheduled maintenance on failure rate and total maintenance cost.

Through the document analysis it was necessary to understand the basis for current cost and availability determination in delivering maintenance. From the document analysis, it was elicited that at present, the ESCIT team utilises parameters called "levers" for the CM. There are five levers and three sub-categories for each one, as shown in Table 2. The levers include:

- People: refers to the different type of people (e.g. skills) required to be able deliver the service and support.

- Spares: refers to the ET level demand for spares.

- Information: refers to the range of information that is required to be able to complete the service and support requirements.

- Test equipment: refers to the test equipment that is required to be able to diagnose the condition of ET.

- Facilities: refers to the facilities required (e.g. hangers) to be able to conduct the maintenance.

These levers represent the resources required in order to deliver CM. Each lever also has subcategories, which are level (e.g. the different sets of skills of maintainers), scale (e.g. the number or quantity) and location (e.g. the physical localisation). The levers define the cost and time that will be invested in $\mathrm{CM}$; and they can be modified to influence the availability and cost in different ways. For example, adjusting the values of the levers is equivalent to establishing safety stock levels. CM activities typically cannot be planned and in order to cope with them, investment in safety stock (in terms of spares, maintainers, etc.) is compulsory. PM activities are scheduled so the cost and time are known, in an approximate way, in advance.

Table 2: Levers used for CM in UK MOD ESCIT

\begin{tabular}{ccc}
\hline Lever & Lever Type & Lever Variable \\
\hline & People & \\
\hline 1.1 & People (maintainers) & Level \\
\hline 1.2 & People (maintainers) & Scale \\
\hline 1.3 & People (maintainers) & Location \\
& Spares & \\
\hline $\mathbf{2 . 1}$ & Spares & Level \\
\hline $\mathbf{2 . 2}$ & Spares & Scale \\
$\mathbf{2 . 3}$ & Spares & Location \\
& Information (Tech Docs) & Level \\
\hline $\mathbf{3 . 1}$ & Information (Tech Docs) & Scale \\
\hline $\mathbf{3 . 2}$ & Information (Tech Docs) \\
\hline $\mathbf{3 . 3}$ & Information (Tech Docs) & Location \\
& Test Equipment & \\
\hline $\mathbf{4 . 1}$ & Test Equipment & Level \\
$\mathbf{4 . 2}$ & Test Equipment & Scale \\
\hline
\end{tabular}




\begin{tabular}{ccc}
\hline 4.3 & $\begin{array}{c}\text { Test Equipment } \\
\text { Facilities }\end{array}$ & Location \\
\hline 5.1 & Facilities & Level \\
\hline 5.2 & Facilities & Scale \\
\hline $\mathbf{5 . 3}$ & Facilities & Location \\
$\mathbf{6 . 0}$ & Preventive Maintenance \\
& Modifications \\
\hline $\mathbf{7 . 1}$ & Modifications & Reliability \\
\hline 7.2 & Modifications & Maintainability \\
\hline 7.3 & Modifications & Redundancy \\
\hline
\end{tabular}

Finally, the combi-lever aggregates the results of each lever as a linear combination to reflect the overall CM requirements. In other words, the effects of each lever are considered independently (i.e. parallel approach) and then aggregated. The document analysis also revealed that the ESCIT team refers to availability and time as the Equipment Available Days (EADs). This captures how many days the equipment will be available for use. The EADs agreed and the maintenance planning must be evaluated in order to accomplish these target days. In MoD, the term "EADs at risk" is used to define the risk of not obtaining the predetermined EADs. The more money is spent on maintenance, the more chance that the EADs will be achieved or the lower the risk of not obtaining the required EADs. However, an optimum balance between money invested and EADs is needed according to the usage requirements of each type of equipment. Accordingly, as the investment increases, the EADS at risk level decreases as the likelihood of achieving the performance target is more achievable. It was also identified that the ESCIT team has developed a methodology to calculate the relationship between availability at risk and cost, through profiles for each lever for a given set of conditions (e.g. EADs required and failure rate). It is also necessary to calculate the aggregate cost and risk for each lever.

This phase of the methodology also involved process development, which was driven by the results from the stages 1-4. In this phase an iterative procedure was followed, which consisted of three semi-structured interviews each lasting two hours with Participant $(1,2,5$ and 6). The key questions that were asked in the interviews included:

- Do you have a failure distribution for each type of equipment recorded?

- Is it possible to represent failures not only with MTBF but also with failure distribution (Weibull/Normal) with data available in MoD?

- Can the impact of alternative resources allocated for $\mathrm{CM}$ be measured in terms of cost and availability?

As an outcome of this phase, an optimisation process was built and embedded into a MS Excel file, which is presented in Section 4. In this phase the feedback from the interviews helped with understanding that there is no established link between any $\mathrm{CM}$ action that has been undertaken and improvement in availability and cost and MTBF. For example, for an individual ET, there is a need to track how often a vehicle breaks down and from there the failure behaviour is reflected. This relies on information from the faults reporting systems. However, the maturity of the data varies for different equipment types and there is rarely $100 \%$ of accuracy and comprehensiveness in the data. It was stated that as a result there is typically further reliance on expert opinion. This factor was realised to be important when considering how to represent failures through probability distributions. Participant 1 and 3 highlighted that "if data is not available we have to guess how this data set would look like and there can be massive holes in data sets". There is an intention to ensure that the data associated to critical parts is mature. The complexity of the data challenge is also associated 
to the changes in the failure rates over time. This in turn creates further challenges with trading between cost and availability/time of CM interventions. In parallel, it was highlighted that the trade-off between how long you need for maintenance and how much time you save because of the maintenance is also of importance and currently there is a lack of processes to assist with this analysis.

This paper focuses on how the $\mathrm{CM}$ activities can be planned. In the process of delivering $\mathrm{CM}$, it was also revealed that there are two main types of scale levers. First, the spares lever works in conjunction with an inventory planner and inventory analyser. Secondly, the queuing levers (people, information, test equipment and facilities) are based on queuing theory models. In the following section, these two main types of levers are explained.

\subsubsection{Spares Lever}

The quantity of spares needed is given by the lever "Scale of Spares". Its output is a ROI profile relating the cost of spares to meet the required availability at a given risk for an ET. This lever works in two steps:

- First, the relation between the safety stock level or First Demand Availability (FDA) and the correspondent availability and availability at risk is calculated. The profile relating FDA with \%EADs at risk is obtained.

- Second, the cost of each safety stock level is calculated, using the inventory planner and inventory analyser. The profile relating to FDA with cost is obtained.

After that, both profiles merge into the final output, \%EADs at risk vs CM cost, which is consistent across all the levers, and allows obtaining the aggregated result through the combi-lever. The impact of having a certain safety stock level on availability is estimated using two main measures: the demand for a particular spare (i.e. equivalent to its failure rate) and the delay that it produces when it is out of stock or DPT (Demand Processing Time). The stock level is common for all the spares for an ET, and the delay is computed as a weighted average for all the parts. Figure 5 shows a histogram recording the delays for spares, used to work out the mean delay for out of stock parts; whereas the formal calculation of EADs lost is given by Equation 2 .

$$
E A D \text { s lost }=\sum_{i}^{n}(\text { Demand for part } i) \cdot(1-F D A) \cdot \overline{D P T}
$$

[Equation 2]

Where the term $(1-F D A)$ represents the probability of spares being out of stock. 


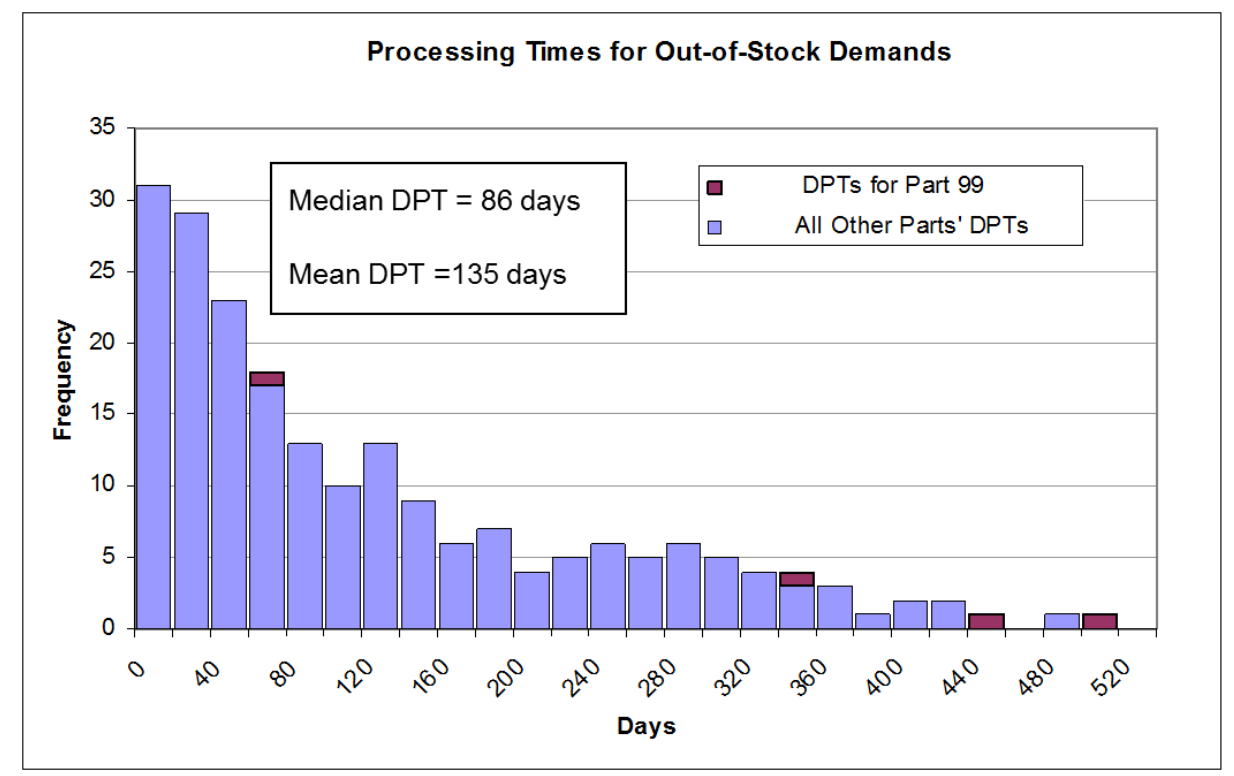

Figure 5. Demand Processing Times (DPTs) for out of stock Demands. Source: ESCIT internal documentation

\subsubsection{Queuing Levers}

As said before, the levers for people, information, test equipment and facilities are based on queuing theory. That means, the availability estimations are drawn from the study of how ET arrives at the maintenance system and waits in the queue for a given number of service points. The queuing model used is the Markovian, single channel, multiple server and infinite source population, or in queuing notation: $\mathrm{M} / \mathrm{M} / \mathrm{c}$ model. The basic assumptions are that the fix time and failure rate follow exponential distributions (i.e. inter-arrival times follow a Poisson process). The source population is infinite, where there is a single queue and the number of servers is the variable that determines the maintenance performance.

However, the inputs available for this model are three point estimates. In fact, the triangular distributions are used to calculate the result at different confidence levels (ten points from $50 \%$ to $99 \%$ confidence level from existing internal project documents), as demonstrated in Error! Reference source not found.6. The idea behind this approach is that at 50\% confidence level $(\mathrm{CL})$, half of the incidences will be covered by the solution of the model; whereas at a higher CL the solution will potentially cope with more failures or longer times to fix. Thus, each $C L$ has a set of inputs artificially/virtually increased to diminish the risk of the solution by subjecting the system to tougher conditions.

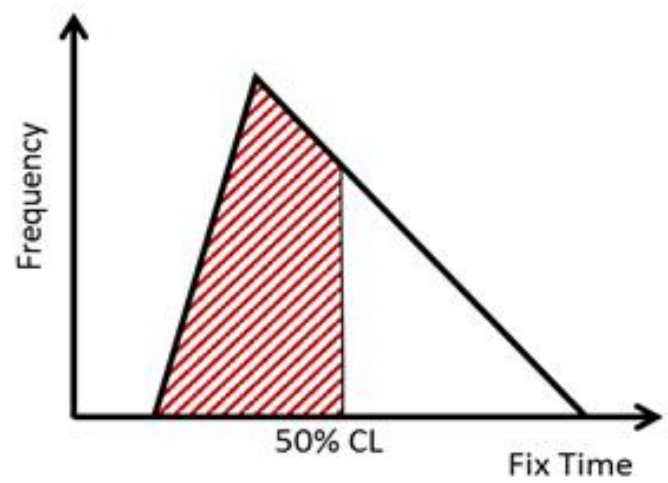

Figure 6. Three point estimate for the Fix Time 
The model outputs the quantity of each resource to meet target availability at each $\mathrm{CL}$, translated in the same form as the spares lever involving: cost versus \%EADs at risk.

\subsubsection{Review of current practices}

Once the current practices, or "As-Is" analysis was performed, the next step consisted of a deductive approach through hypothesis testing (both qualitatively and quantitatively). This is to review and validate all the assumptions within the support planning process.

The review of the Spares levers followed an eminently qualitative analysis based on discussion of the assumptions and suggestions for improvement with the ESCIT Team.

The "Queuing levers" were studied in a similar manner: assessing the accuracy of the model hypothesis. As explained before, the Scale of People, Information, Test Equipment and Facilities are based on an infinite source queuing model. In particular, they are based on the so called multiple server, single channel and infinite population source. The main issues with this model are:

- Maintenance systems normally work with a finite population source. An infinite source could model the maintenance in a garage, which has potentially an infinite source of customers, or how customers queue in the supermarket tills.

- Queue instability: if arrival times outweigh the throughput of the system, the queue would grow to infinite, and this model does not provide a solution.

Therefore, a more suitable model is studied: a multiple server, single channel and finite population source. The main differences and advantages of the finite model are:

- The probability of new ET failure is reduced when the active population is reduced.

- The queues are always stable.

Theoretically, the finite model is only affected by the average failure rate, but not its distribution (Gross and Harris, 1985). However, it still assumes the fix time follows an exponential distribution. As explained in Section 3.2.2, the ESCIT team works mostly with three point estimates for these inputs. The concern was to what extent the fix time distribution affected the results and if the failure rate distribution did not actually change the system performance. Both issues were tested using Discrete Event Simulation by modelling a simple maintenance system. DES was used to study the effects of having different input distributions because that would have been impossible to do analytically. Apart from that, a more mature fix time data set (in air environment, where failure and fix records are kept more precisely) was studied to assess its fit to either a triangular or an exponential distribution. Finally, the definition of EADs at risk was reviewed and a new more robust risk definition was proposed, as explained in Section 4.

\subsection{Further refinement (Soft Systems Methodology stages 5 and 6)}

The process of validating the collated cost and availability drivers and maintenance processes included two workshops (attended by Participants 5-6 in the two instances). The refinement was conducted around defining the key drivers of cost and availability for $\mathrm{CM}$ activities.

Once the proposed finite queuing theory model was approved and the previously described issues were tested, the next step consisted of implementing the model across all the Scale 
and Location levers. The task was a reprogramming of the lever tools embedded in spreadsheets. As the finite model was implemented, it was tested at two stages against its infinite counterpart, using a real Land vehicle case study data set, including:

- Test for Scale of People lever for comparison against the infinite model.

- Test at combi-lever stage: test of the combined result of the levers for comparison against the infinite model.

\subsection{Development of software tool for CM resource trade-off analysis for cost and availability (Soft Systems Methodology stage 7)}

An optimisation model was developed using MS Excel. It focuses on aiding engineering teams involved in delivering maintenance and guides with $\mathrm{CM}$ activities. The platform of Excel was selected based on industrial requirements due to its vast availability and due to the flexibility it offers. This final stage involved two workshops that were attended by 6 participants (Participants 1-6). These workshops focused on using real life data to test (whereby two cases from the land and aircraft domain) the optimisation process that has been developed. The finalised model was presented and validated by the informants of the study based on completeness of model to estimate cost and availability of $\mathrm{CM}$ actions.

\section{Proposed approach for Corrective Maintenance Optimisation}

In Section 3, the current practice for estimating the impact that spares has on availability was introduced, as shown in Equation 3:

$$
E A D s=\sum_{i}^{n}(\text { Demand for part } i) \cdot(1-F D A) \cdot \overline{D P T}
$$

[Equation 3]

This approach presents two main sources of inaccuracy:

- The use of a mean DPT: there are significant differences among DPT of parts

- The use of a single value of FDA (safety stock) for the whole ET: not all parts would need the same level of safety stock

In order to improve on these challenges, the model has been adapted as Equation 4]:

$$
E A D s=\sum_{i}^{n}(\text { Demand for part } i) \cdot\left(1-F D A_{i}\right) \cdot D P T_{i}
$$

[Equation 4]

- Use of a mean DPT for each part (or group of parts) offers improved availability prediction

- Use a safety stock level (FDA) for each part (or group of parts) offers improved cost estimation and potential cost savings

Hence, the logic behind the proposal is to carry out a Pareto-type analysis to group parts, then establish a rational range for the safety stock of each group and use the lever adjusting that safety stock within the calculated range (i.e. plus or minus a percentage for all the parts at the same time). Despite the proposals previously presented were found logical and 
agreed by the ESCIT team, the suggestions were discussed with the Team Leader and the following constraints were found:

- Grouping: the criteria to group spares can be dynamic depending on needs, faults, costs, equipment usage, etc. The groups could easily be revised and updated (Inventory Management) whereas its practical application would be very difficult (Inventory Control).

- Coding: the spares grouping would require retagging/reorganising the spares for every update, which represents a significant cost through the huge amount of spares for all the ETs.

- The correct or appropriate value for the safety stock of each group can be difficult to establish.

- Inventory analyser and Inventory planners (which are part of the process) have aging software constraints, and they are different for the different divisions (Air, Land, and Sea).

Therefore, the "Scale of Spares" lever could be improved in accuracy in the way explained previously, but the above constraints make it rather challenging.

\subsection{Queuing Levers}

As introduced in the research methodology the assumptions for the queuing levers were reviewed taking in to account: the queuing model itself, its inputs and the availability at risk definition, which is critical when analysing the maintenance delivery.

\subsubsection{Finite Source Queuing Model}

As explained in Section 3.2, the current approach for maintenance planning is the use of an infinite population queuing model (shown in Figure 7A, where $\lambda$ is the failure rate and $\mu$ is the service time). The levers have an embedded protection against queue instability (when arrivals are faster than service) and maximum queue length (as the fleet is finite). This restricts the solutions and the accuracy of the result is compromised._Because of that, a finite source queuing model was explored (as shown in Figure 7B).
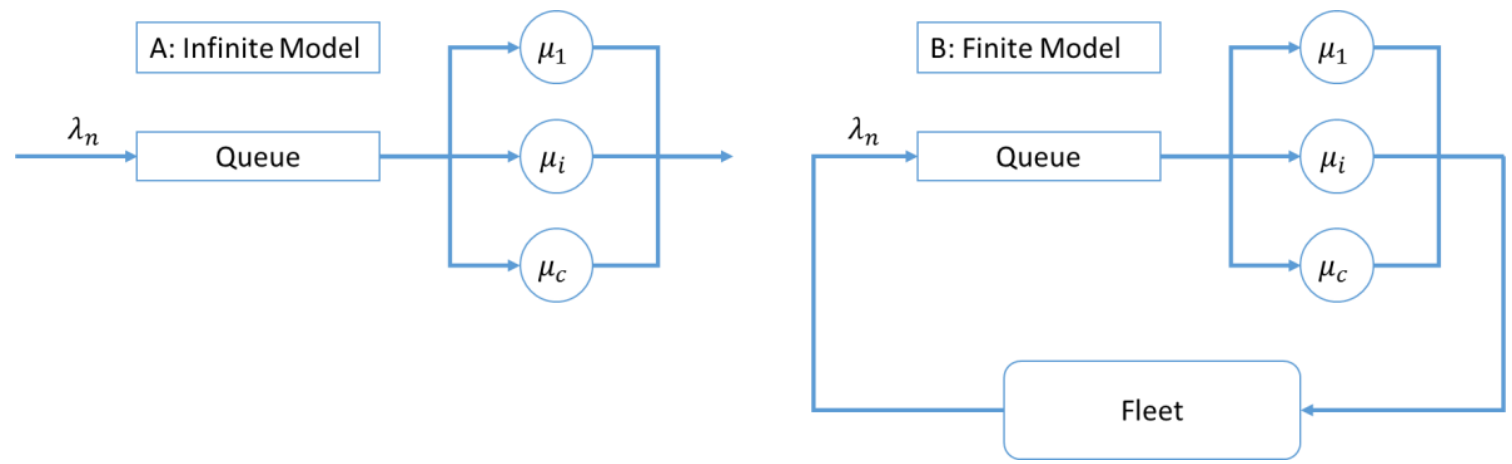

Figure 7A) Infinite population source queuing model. 7B) Finite population source queuing model.

The premises for the finite queuing model are (Gross and Harris, 1985): 
- Failure Rate is exponential and follows (note that this assumption has been corrected $^{2}$ ):

$$
\lambda(n)=\left\{\begin{array}{cc}
\frac{M-n}{M} \lambda, & 0 \leq n<M \\
0, & n \geq c
\end{array}\right.
$$

[Equation 5] where: $M$ is the size of the fleet, $n$ is the number of ET in the maintenance system and $\lambda$ is the characteristic failure rate of the ET. This means that the failure rate reduces when more ET are in the maintenance system

- And Fix Time follows:

$$
\mu(n)=\left\{\begin{array}{lr}
n \mu, & 0 \leq n<c \\
c \mu, & n \geq c
\end{array}\right.
$$

[Equation 6]

where: $\mu$ is the maintenance rate and $c$ is the number of maintenance crews. The system gives maximum throughput when all serves are busy.

The main advantages of the finite model compared to the infinite approach are:

- It always works: there is no queue instability for any value of failure rate, fix time or number of crews.

- Its accuracy is better: the infinite model underestimates performance as it assumes a possible infinite number of arrivals; whereas the maintenance system is indeed servicing a finite fleet.

- Failure distribution does not affect result: literature states that only the mean failure rate defines the result, but not its distribution.

The main disadvantage of the finite model is the increase in complexity, but it is still straightforward to embed in a spreadsheet. A first study of the queuing model was performed before proceeding to its implementation. In Table 3 the characteristic performance measures in queuing theory are presented for both models under the same conditions. This illustrates the main differences and advantages previously presented.

Table 3: Performance measures for infinite and finite models under the same conditions

\begin{tabular}{|l|c|c|c|c|c|c|}
\hline Breakdown Rate & \multicolumn{5}{c|}{0.042} \\
\hline Fix Time (h) & \multicolumn{2}{|c|}{48} \\
\hline Fleet size (number) & \multicolumn{2}{|c|}{3} & \multicolumn{2}{c|}{3} \\
\hline \\
\hline No of crews (number) & \multicolumn{2}{|c|}{2} & \multicolumn{2}{c|}{3} \\
\hline & Infinite & Finite & Infinite & Finite & Infinite & Finite \\
\cline { 2 - 7 } Avg. no. of ET in system & $\infty$ & 1.26 & 2.89 & 1.20 & 2.89 & 2.64 \\
\hline Avg. no. of ET in queue & $\infty$ & 0.09 & 0.89 & 0.00 & 0.89 & 0.69 \\
\hline Waiting time in system (h) & $\infty$ & 51.8 & 69.3 & 48.0 & 69.3 & 65.1 \\
\hline
\end{tabular}

\footnotetext{
${ }^{2}$ Correction of finite model assumption: the definition in literature does not consider the term dividing by the fleet size (M), which leads to non-convergence of the sums and therefore to incorrect results.
} 
The first test proved the theoretical advantages of the finite model. It can be seen that the waiting times and queue lengths are lower for the finite model. Moreover, when the population is fairly big the results differ slightly, whereas for small populations the differences are very significant. The finite model was implemented across the queuing levers. The results that compare both models are presented in the following sub-sections.

\subsubsection{Input distributions}

The ESCIT team works with three point estimates for all the maintenance related inputs. However, the analytical resolution for both the infinite and finite model is based on an exponential failure rate and time to fix. In other words, the three point estimate is used to calculate an average (and the value for the inputs at each confidence level) but after that, the service time is assumed to be exponential. A simple DES representation of the finite source model was built to test how changing the arrival and service behaviours would affect the performance of the system. The elements of the model are described in Table 4 and illustrated in Figure 8

Table 4: Discrete event simulation model components

\begin{tabular}{|c|c|c|c|}
\hline Item & Type & Description & Characteristics \\
\hline$E T$ & Part & $\begin{array}{l}\text { Each part represents } \\
\text { an ET }\end{array}$ & $\begin{array}{l}\text { All the fleet of ET enters the } \\
\text { system at the beginning }\end{array}$ \\
\hline Fleet & Buffer & Represents the fleet & Capacity is bigger than fleet size \\
\hline Failure & $\begin{array}{l}\text { Single } \\
\text { machine }\end{array}$ & $\begin{array}{l}\text { Represents the failure } \\
\text { that moves an ET from } \\
\text { the active fleet to the } \\
\text { maintenance system }\end{array}$ & $\begin{array}{l}\text { The machine cycle time } \\
\text { represents the mean time } \\
\text { between failure (it can follow } \\
\text { several distributions) }\end{array}$ \\
\hline Queue & Buffer & $\begin{array}{l}\text { Represents the queue } \\
\text { of ET waiting for } \\
\text { maintenance }\end{array}$ & Capacity is bigger than fleet size \\
\hline Maintenance & $\begin{array}{l}\text { Single } \\
\text { machine }\end{array}$ & $\begin{array}{l}\text { Each machine } \\
\text { represents a service } \\
\text { point or maintenance } \\
\text { crew }\end{array}$ & $\begin{array}{l}\text { The machine cycle time } \\
\text { represents the time to fix (it can } \\
\text { follow several distributions) }\end{array}$ \\
\hline
\end{tabular}


Figure 8 provide discrete event model representation of the finite source model that was built to test how changing the arrival and service behaviours would affect the performance of the system. The failure rate was tested for exponential and Gaussian distributions; while the time to fix was studied for exponential and triangular distributions.

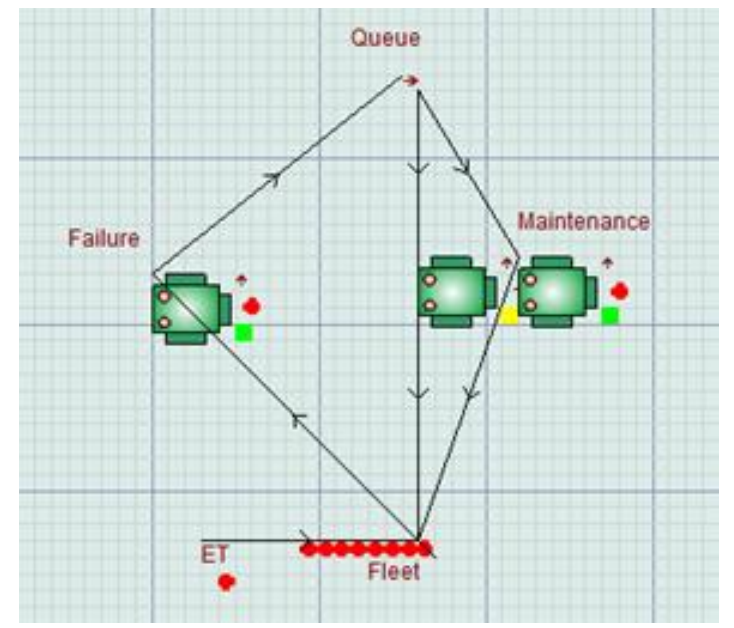

Figure 8. Discrete event simulation model (Witness ${ }^{\circledR} 13.0$ software)

The failure rate was tested for exponential and Gaussian distributions; while the time to fix was studied for exponential and triangular distributions. The results shown in Table 5 are for the finite model performance under the same average conditions for a given case study provided by ESCIT, whilst just changing the probabilistic shape of the arrivals and the queue for service times.

Table 5. Average time waiting in queue for different service and inter-arrival times

\begin{tabular}{|c|c|c|c|c|}
\hline \multirow[b]{2}{*}{ Trial } & \multicolumn{4}{|c|}{ Average time waiting in queue (h) } \\
\hline & $\begin{array}{l}\text { Exponential } \\
\text { failure rate }\end{array}$ & $\begin{array}{c}\text { Gaussian failure } \\
\text { rate }\end{array}$ & $\begin{array}{l}\text { Exponential } \\
\text { service }\end{array}$ & $\begin{array}{c}\text { Triangular } \\
\text { service }\end{array}$ \\
\hline 1 & 15.6 & 15.5 & 16.3 & 2.8 \\
\hline 2 & 19.1 & 14.4 & 13.6 & 2.8 \\
\hline 3 & 16.0 & 12.9 & 12.4 & 2.8 \\
\hline 4 & 16.8 & 14.9 & 12.8 & 2.6 \\
\hline 5 & 16.6 & 12.3 & 17.5 & 2.6 \\
\hline 6 & 11.9 & 16.9 & 15.2 & 2.5 \\
\hline 7 & 14.8 & 18.3 & 18.4 & 2.5 \\
\hline 8 & 17.5 & 12.6 & 14.1 & 2.9 \\
\hline 9 & 13.6 & 14.5 & 11.1 & 3.0 \\
\hline 10 & 16.6 & 13.6 & 12.5 & 2.5 \\
\hline Moving average & 15.5 & 14.7 & 14.4 & 2.7 \\
\hline
\end{tabular}

From Table 5, it can be seen that the performance is independent of the failure distribution, as stated by literature. So, the level of maturity of the failure records will not affect accuracy as much, as long as the average failure rate is representative of reality. On the other hand, fix time distribution does affect the performance significantly. Even though literature says that exponential service time is a reasonable assumption when treating maintenance problems (Gross and Harris, 1985), as jobs are variable, independent and memoryless, this 
has to be tested. The main problem is that these are not accurate (nor well-structured) fix time records for many ET. So, the test of this assumption was limited to some examples where data records were kept more precisely. Results for an air fix time record from ESCIT can be seen in Figure 9. At first sight it can be seen that the data approximates more to an exponential than to a triangular distribution.

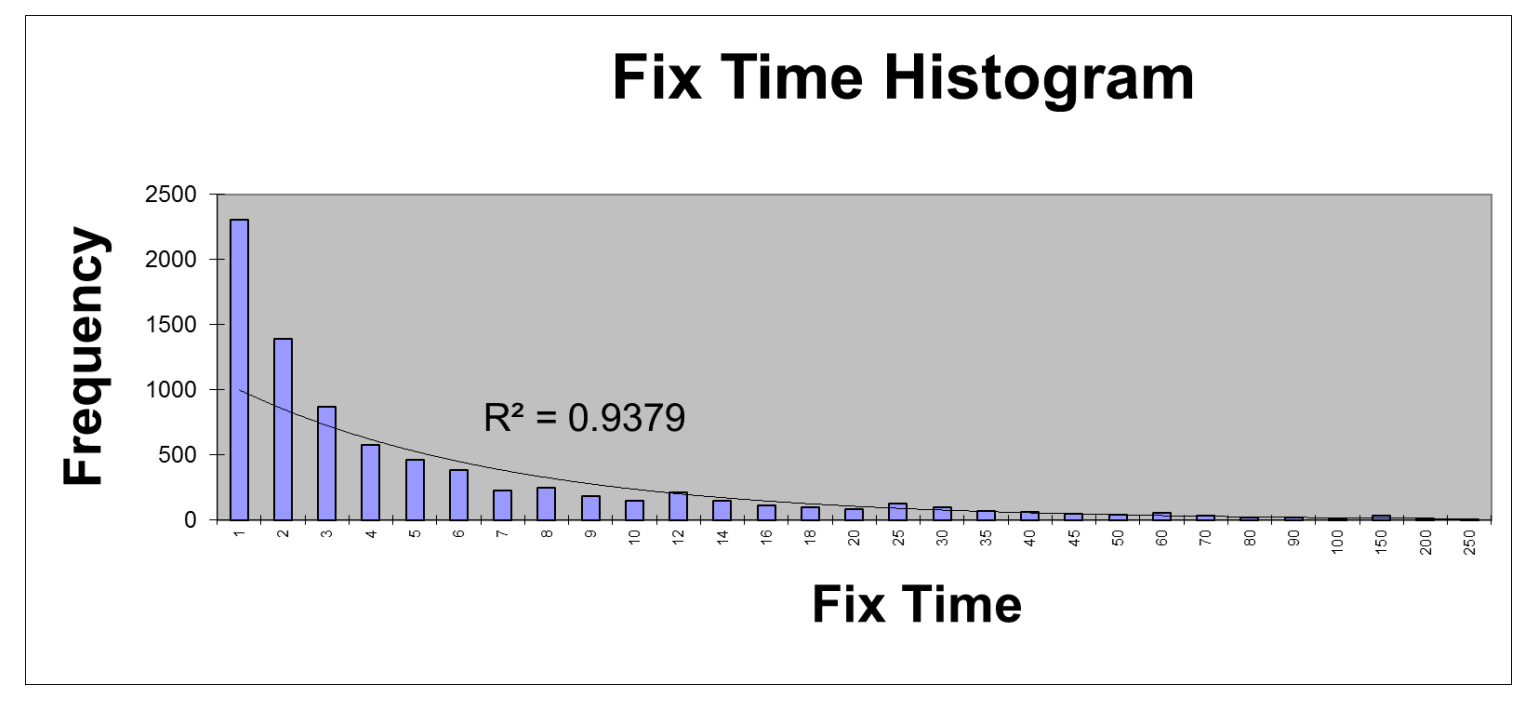

Figure 9. Aircraft time to fix histogram. Source: ESCIT internal records.

Even though the R-squared value indicates a fairly poor fit to an exponential, it is still a reasonable approximation when considering that it enables having an analytical solution (which simplifies the decision process).

\subsubsection{Evaluating the availability at risk definition}

The queuing theory makes many assumptions about the way risk affects the maintenance system. A fleet of ET will produce a certain quantity of EADs during a given period (the so called time period of the lever, typically 365 days). Ideally, the maximum days available would be the fleet size multiplied with the time period. From these maximum days, some will be lost due to $\mathrm{CM}$, while others will be caused by PM. Apart from that, target availability will be set, which is the required demand. The days spent in PM will be deterministic while the lost days due to $\mathrm{CM}$ will be estimated by the average number of ET days in the maintenance system (i.e. they depend on the maintenance system performance). For instance, if there are ten ET days for maintenance on average, at the end of the year, 3650 days would be lost due to $\mathrm{CM}$. Those lost days result from the steady state solution of the queuing model. However, the real result could differ significantly from the mean based one. Therefore, it is useful to quantify what is the risk of the predicted availability not meeting the target.

The lost days in $\mathrm{CM}$ at each confidence level are calculated assessing how the system would perform at $50 \%$ confidence level but with the amount of resources of the given confidence level. Then, the EADs at risk are the fraction of those lost days that are not covered by the confidence level (e.g. a $30 \%$ of the lost days in $\mathrm{CM}$ are at risk in the $70 \%$ confidence level). The EADs at risk definition is shown in Equation Error! Reference source not found., and a graphical representation is shown in Figure 10:

$E A D$ s at risk $=(1-C L) \cdot E A D$ s lost in $C M$ 
[Equation 7]

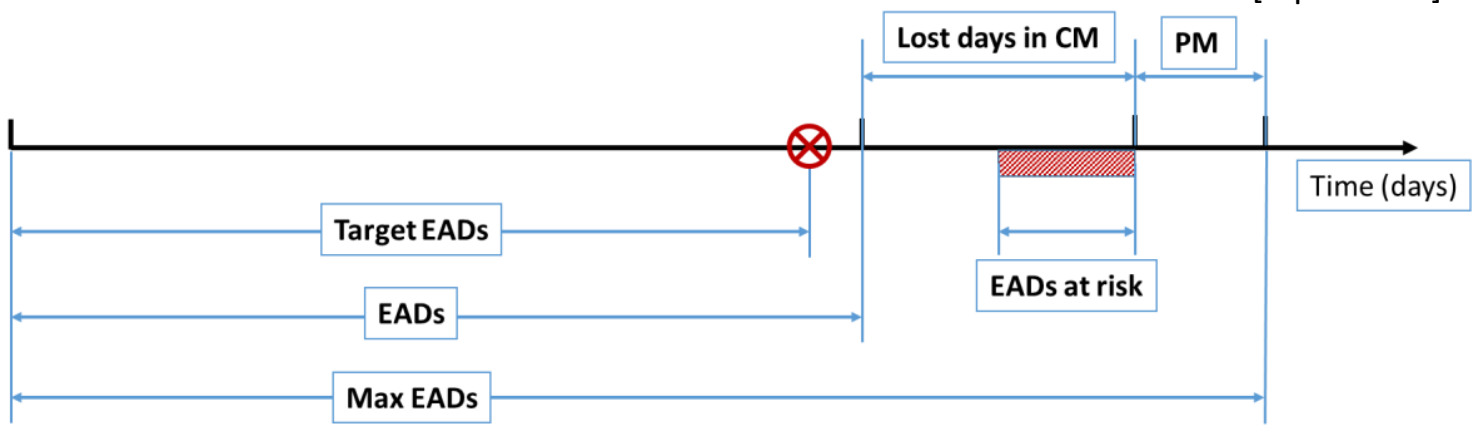

Figure 10. Graphical representation of the availability estimates and their interrelations based on the existing availability at risk definition.

The underlying assumption is that the confidence level represents what percentage of the solution is known; while the value $(1-C L)$ represents the uncertain part of the behaviour. This existing approach presented two main problems: first, the definition of EADs at risk does not take into account the required availability. In other words, suppose the available EADs leave a margin with respect to the target EADs. If that margin was big enough to absorb part of the calculated EADs at risk, then the risk should be lowered, as there is a degree of "safety stock". Second, as the lost days in CM are evaluated at the $50 \%$ confidence level the risk is not as conservative as it could be.

To address this issue, a slightly different definition for risk is proposed. The basic assumption remains the same, but now, the difference between target and available EADs is accounted for. Also, the lost days in $\mathrm{CM}$ are taken from the performance at each confidence level. The new definition is shown in Figure 11 and expressed in Equation 8.

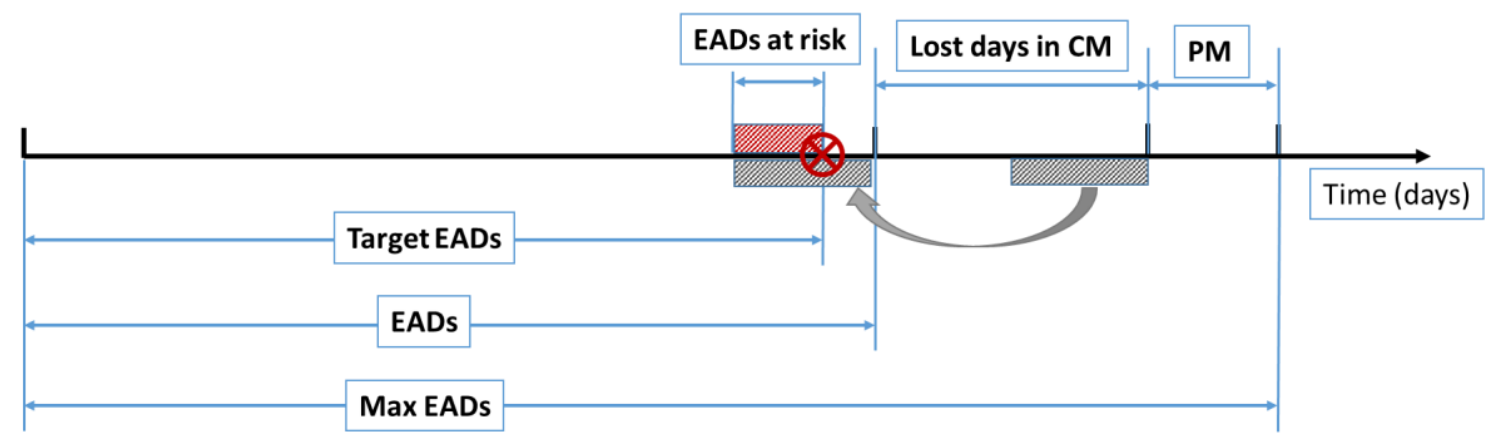

Figure 11. Graphical representation of the availability estimates and their inter-relations with the new availability at risk definition

EADs at risk $=(1-C L) \cdot E A D$ s lost in $C M-[E A D s-$ Target EADs $]$

[Equation 8]

The enhanced risk definition is like the previous EADs at risk definition but takes in to account the margin left between the available and target EADs. This margin could increase or decrease the risk depending on its sign. Nonetheless, the main difference arises because the lost days in $\mathrm{CM}$ result from the performance at each confidence level. A real example of 
the difference in results from a land based case study between the two definitions is shown in Figure 12. In conclusion, the new definition provides a more conservative risk calculation.

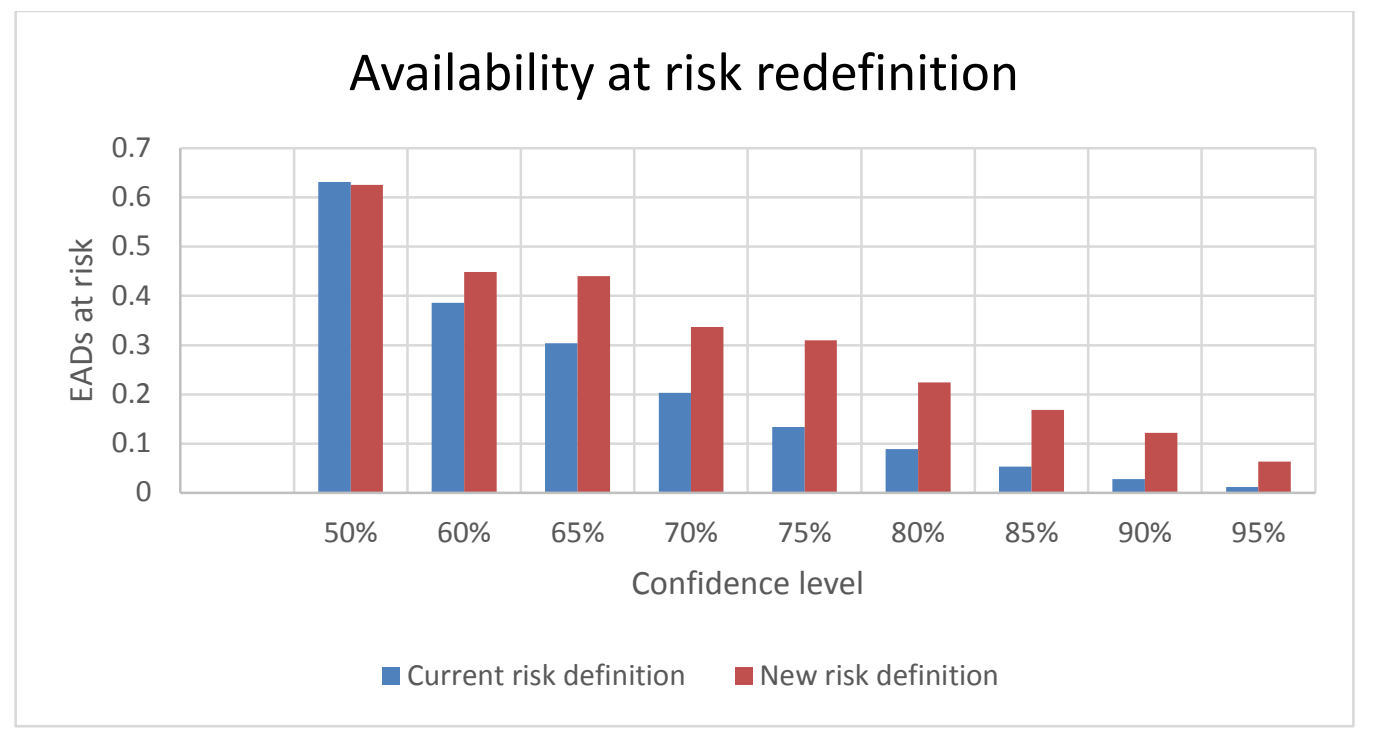

Figure 12. Comparison of the two risk definitions (Land vehicle case study)

\section{Model implementation and validation results}

\subsection{Overview of the case study}

After implementing the finite queuing model across all the levers, a land vehicle case study was used for validation. First, the results are compared to the infinite queuing model; next, the results including the availability at risk redefinition are presented; and finally, an example of the aggregated result using the combi-lever is shown. The set of inputs for the Scale of people is presented in Table 6 .

Table 6: Data set for the "Scale of People" lever for the Land vehicle case study

\begin{tabular}{|c|c|c|}
\hline & INPUT & VALUE \\
\hline \multirow[t]{3}{*}{ Maintainer Hours (per month) } & Most likely & 107 \\
\hline & Worst Case & 95 \\
\hline & Best Case & 113 \\
\hline \multirow[t]{3}{*}{ Fix Time (in Hours) } & Most likely & 3.26 \\
\hline & Worst Case & 9 \\
\hline & Best Case & 0.5 \\
\hline \multirow[t]{3}{*}{ Breakdown Rate (Per Hour) } & Most likely & 0.91 \\
\hline & Worst Case & 1.25 \\
\hline & Best Case & 0.43 \\
\hline \multicolumn{2}{|c|}{ Number of Equipment Type instances operating } & 40 \\
\hline \multicolumn{2}{|c|}{ Required EAD's (Demand) } & 5360 \\
\hline \multicolumn{2}{|c|}{ Number of People in a crew (Crew Size) } & 2 \\
\hline \multicolumn{2}{|c|}{ Capitation rate (f thousands) } & 36.71 \\
\hline \multicolumn{2}{|c|}{ Time Period of Lever (in days) } & 365 \\
\hline \multicolumn{2}{|c|}{ Days Equipment Type is in Scheduled Maintenance } & 2440 \\
\hline
\end{tabular}




\subsection{Comparison of the finite and infinite queuing modelling approaches}

The land case study results are for the "Scale of People" lever, and therefore they indicate the cost of the maintainers necessary to meet demand at the ten confidence levels and its correspondent availability at risk. The results for the lever profiles are shown in Figure 13. Accordingly, 0\% EADS at risk refers to the confidence in achieving the performance targets with the set cost of maintainers. The costs between the finite and infinite models vary significantly.

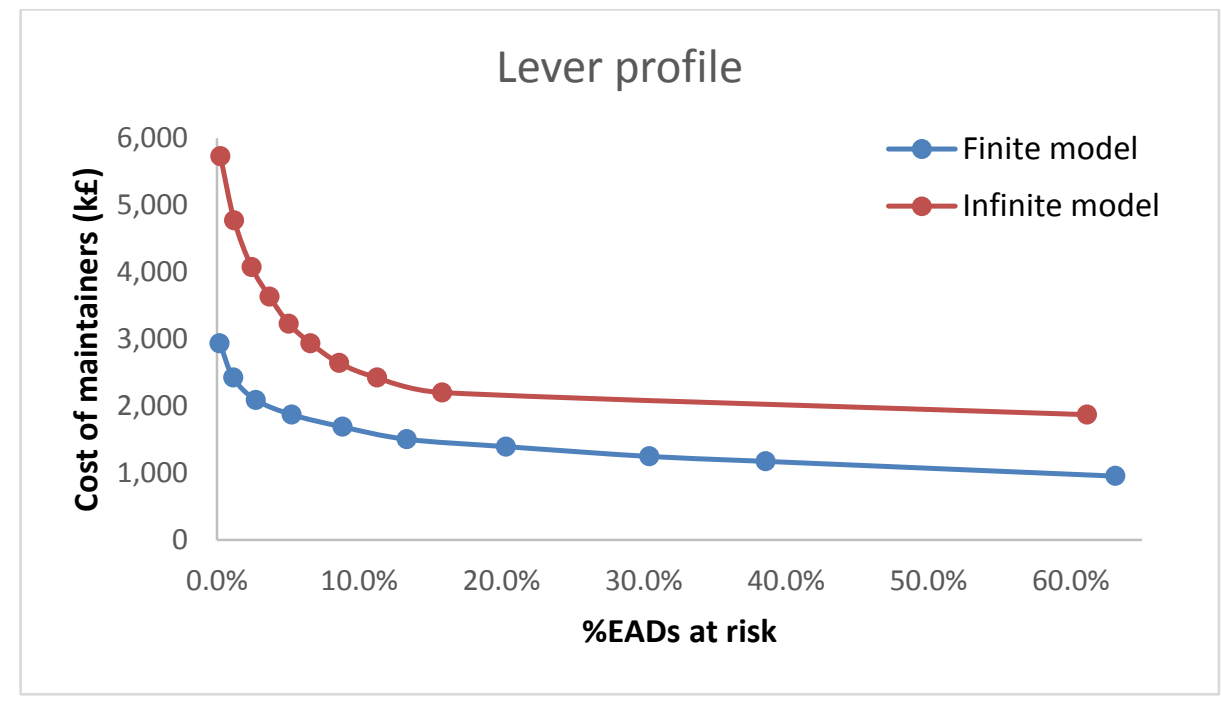

Figure 13. Lever profiles for both queuing models under the same conditions

Each point in the curve represents a confidence level (from $50 \%$ to $99 \%$ ). It can be seen that the lever profile is displaced down and to the right with the finite model. On one hand, this means that less resource is needed to meet the same availability. As an example, at \% EADS at risk level the cost of the maintainers with the infinite model is significantly higher than the results attained from the finite model. The significant difference between both models arises because the infinite model finds the solution that avoids the queue to become unstable as it is assuming that the possible arrivals are infinite. Conversely, the finite model can cope with the same situation with less resources because the more failures occur, the less ET are prone to fail, thus the queue is always stable and it can never grow more than the fleet size. Nevertheless, both models present a steep increase in cost when moving towards the low risk figures (or high confidence levels). This occurs because the outputs are modified at each confidence level (according to the triangular distribution); so, the higher the confidence level, the more demanded is the system and therefore more resources are needed.

The main problem with this is the triangular distribution does not offer a realistic increase in the inputs. The queuing models work with exponential distributions, but the inputs are worked out as three point estimates. In Figure 14, the cumulative probability functions for both distributions show that for the same confidence level, the triangular gives higher values for the inputs. As a result, cost is overestimated because the system is subjected to worse conditions. 


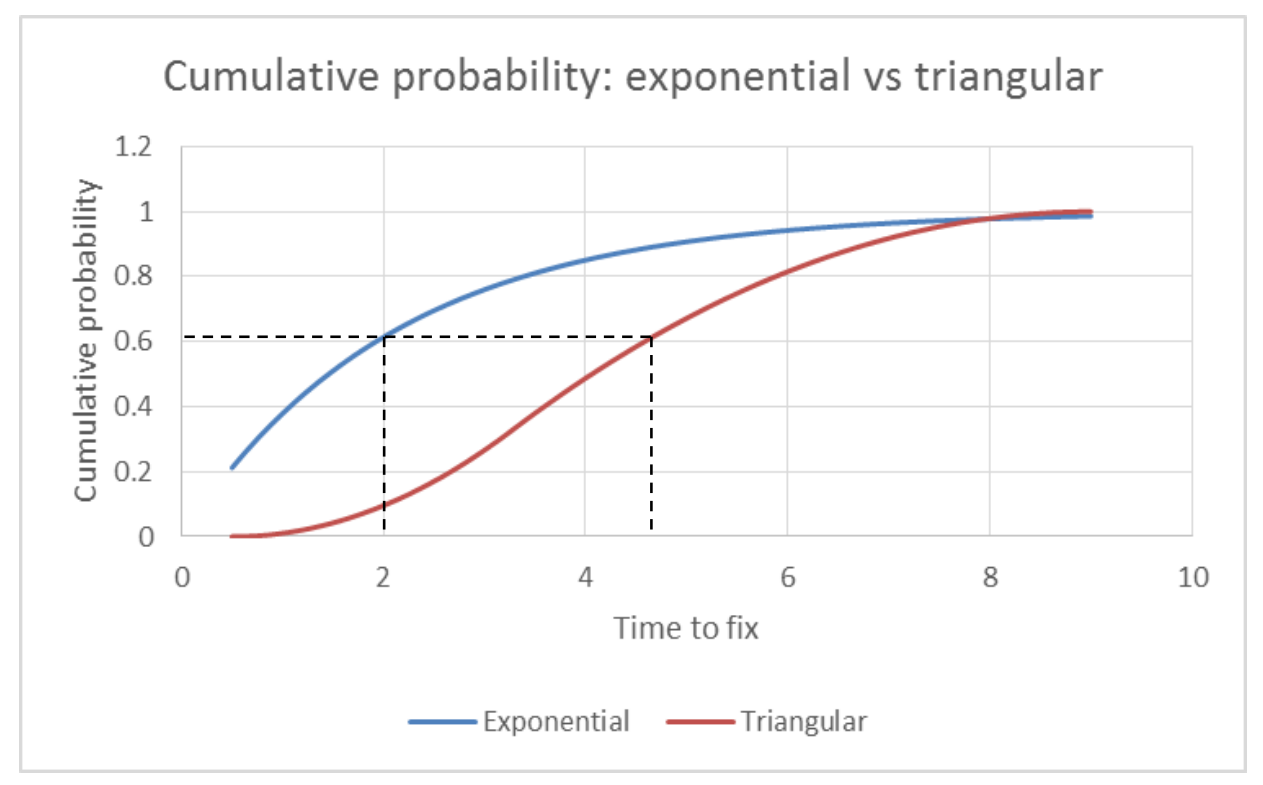

Figure 14. Cumulative probability functions for exponential and triangular distributions.

\subsection{Role of risk in queuing models}

When the updated availability at risk definition is included, the behaviour of the finite model does not change (the same resources are needed at each confidence level) but the risk is managed in a more conservative way, as explained in section 4.1.3. The results that compare the finite model with the two risk definitions are shown in Figure 15. The corresponding points at each confidence level are at the same cost, but the red curve is displaced to higher risks. Therefore, the new finite queuing model plus the risk redefinition provide together a reduction in the cost estimation and an extra protection against demand not being met. In addition, an example, using the same land based case study data of comparing the aggregated result given by the combi-lever for the infinite and finite models is shown in Figure 16. It can be seen that the behaviour follows the same pattern as in the individual lever results: less resources are needed and risk is more conservative.

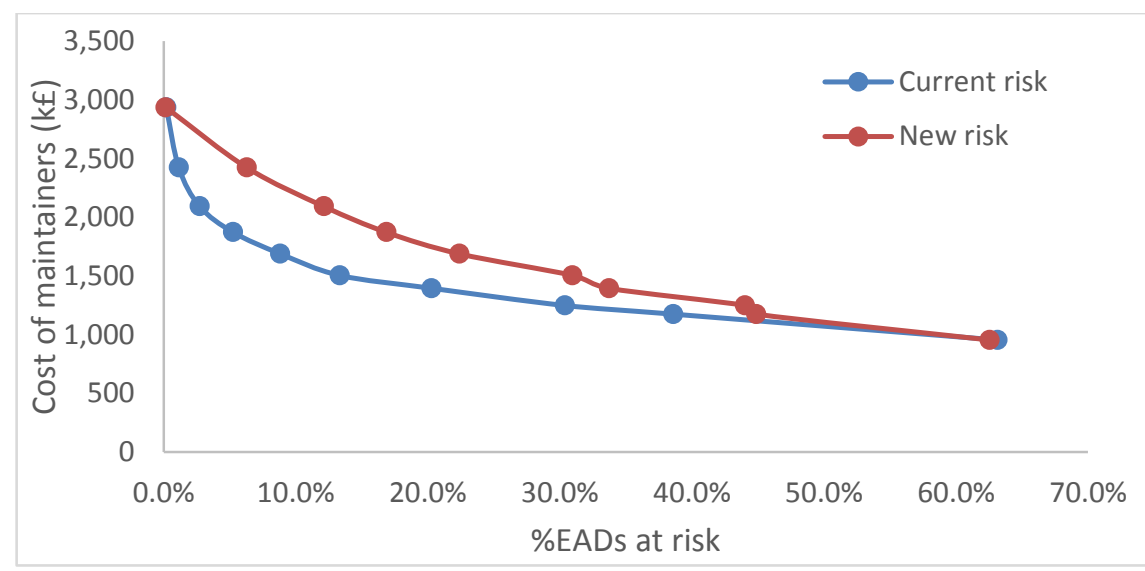

Figure 15. Finite source lever profiles comparing the two risk definitions 

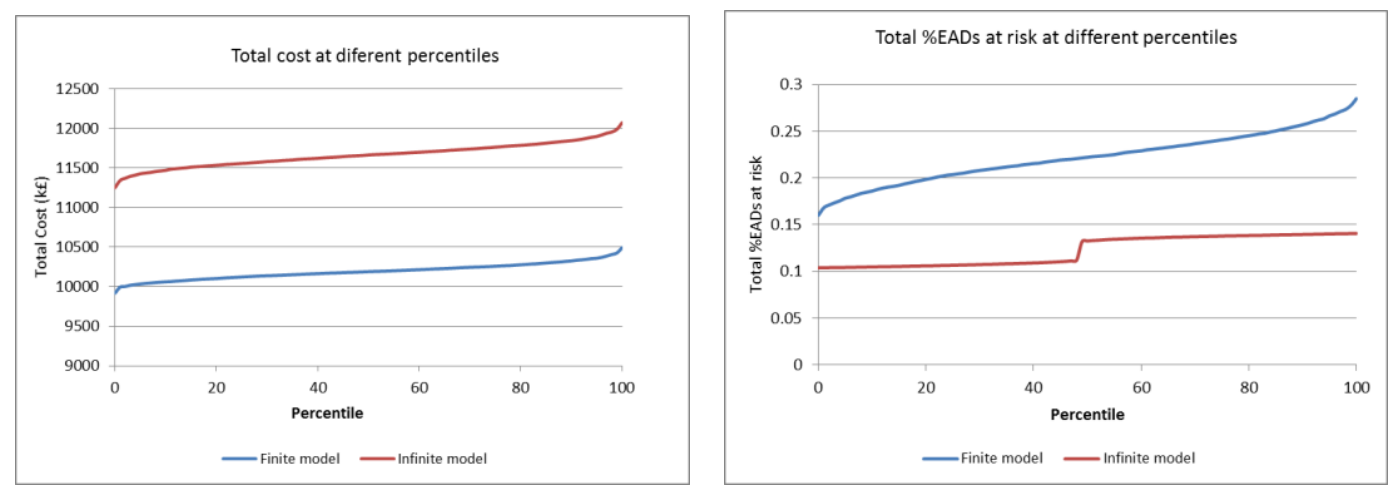

Figure 16. A) Aggregated cost for both models and B) \% EADS at risk for both models

Note that the format of the results in the combi-lever separates both outputs (cost and risk) and links them by a percentile value. For instance, the results at the $80 \%$ percentile are shown in Table 7:

Table 7: Aggregated cost and availability at risk for both models at the $80^{\text {th }}$ percentile

\begin{tabular}{r|c|c|}
\multicolumn{2}{|c}{ INFINITE } & \multicolumn{1}{c}{ FINITE } \\
\hline COST (thousands $f$ ) & 11,800 & 10,300 \\
\hline$\%$ EADs at RISK & $13.9 \%$ & $24.7 \%$
\end{tabular}

\subsection{Results for sensitivity analysis}

A sensitivity analysis was performed to study the influence of the $\mathrm{CM}$ related inputs on the cost and availability results and rank them in order of importance. For this process Elementary Effects Method was adopted (Morris, 1991; Campolongo et al., 2007). The basics of this method are studying how the elementary effects for each input behave. The elementary effect results from changing one input at a time, exploring its possible values, and comparing the distortion in the result with the change in the input, both with respect to a baseline. For each input, a series of elementary effects is obtained. Each series of elementary effects follows a certain distribution (characterised by its mean and standard deviation), which indicates what type of effect has the particular input over the result. This method classifies them qualitatively in: a) negligible effect, b) linear effect, c) non-linear effect or d) involved in interactions with other inputs. The last two are indiscernible through this method.

Each input is characterised by the mean $(\mu)$, the mean of the absolute values $\left(\mu^{*}\right)$ and the standard deviation $(\sigma)$ of its elementary effect distribution. The values for $\mu^{*}$ indicate how much the input affects the output, i.e. a value close to one means that the input influences the result in a proportion of 1:1. On the other hand, the values for $\sigma$ represent the "linearity" of that effect. The higher the standard deviations, the higher is the non-linear influence. In this case, the sensitivity analysis has been performed for both the cost and risk at the 50\% confidence level, using the Land Case Study for the "Scale of People". The results are presented in Table 8 and further illustrated in Figure 17 and Figure 18. The sign in the values for $\mu$ indicate direct or inverse proportionality. 
Table 8: Means and standard deviations of the elementary effects distributions for each input

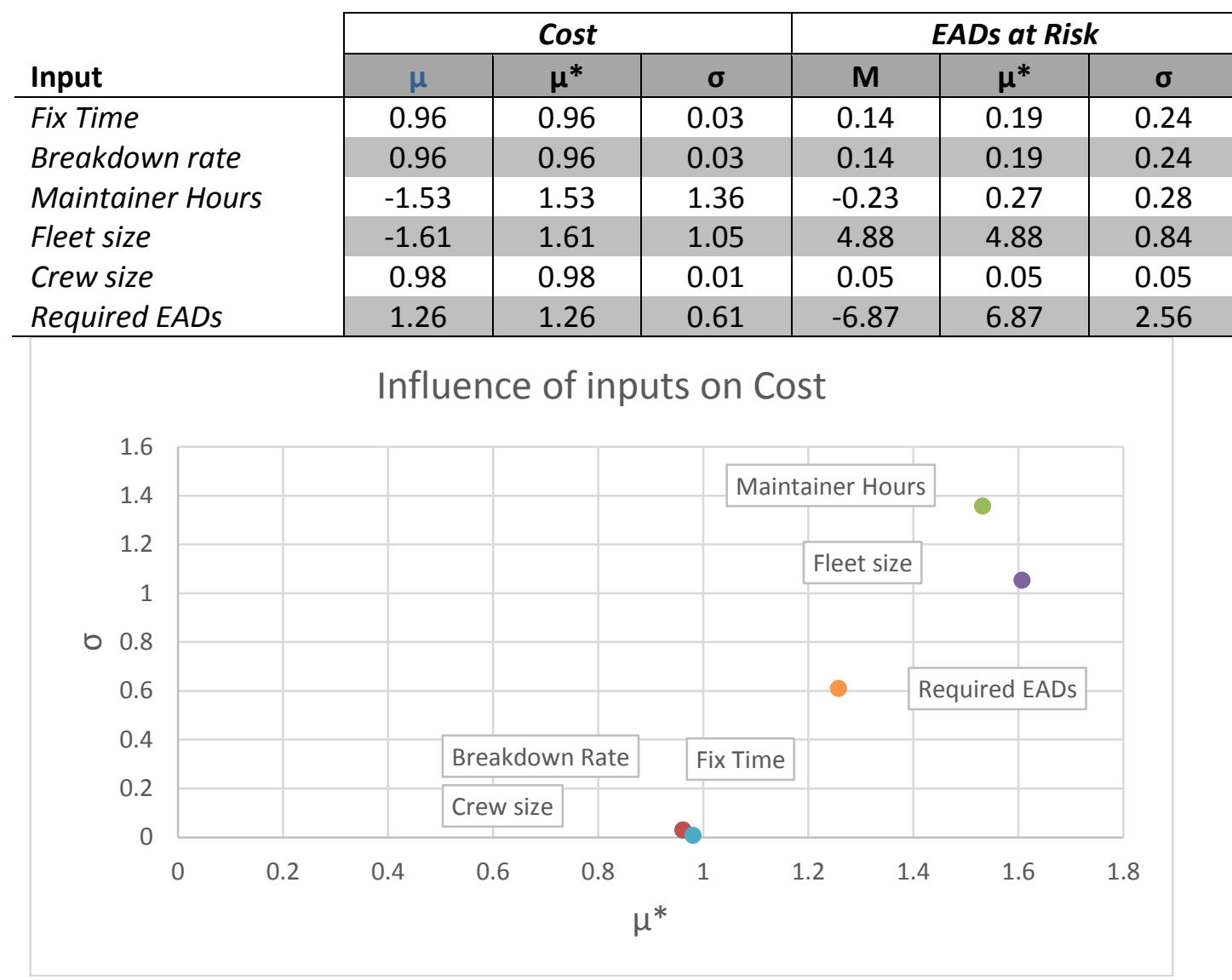

Figure 17. Plot of the two sensitivity measures for each input affecting the cost

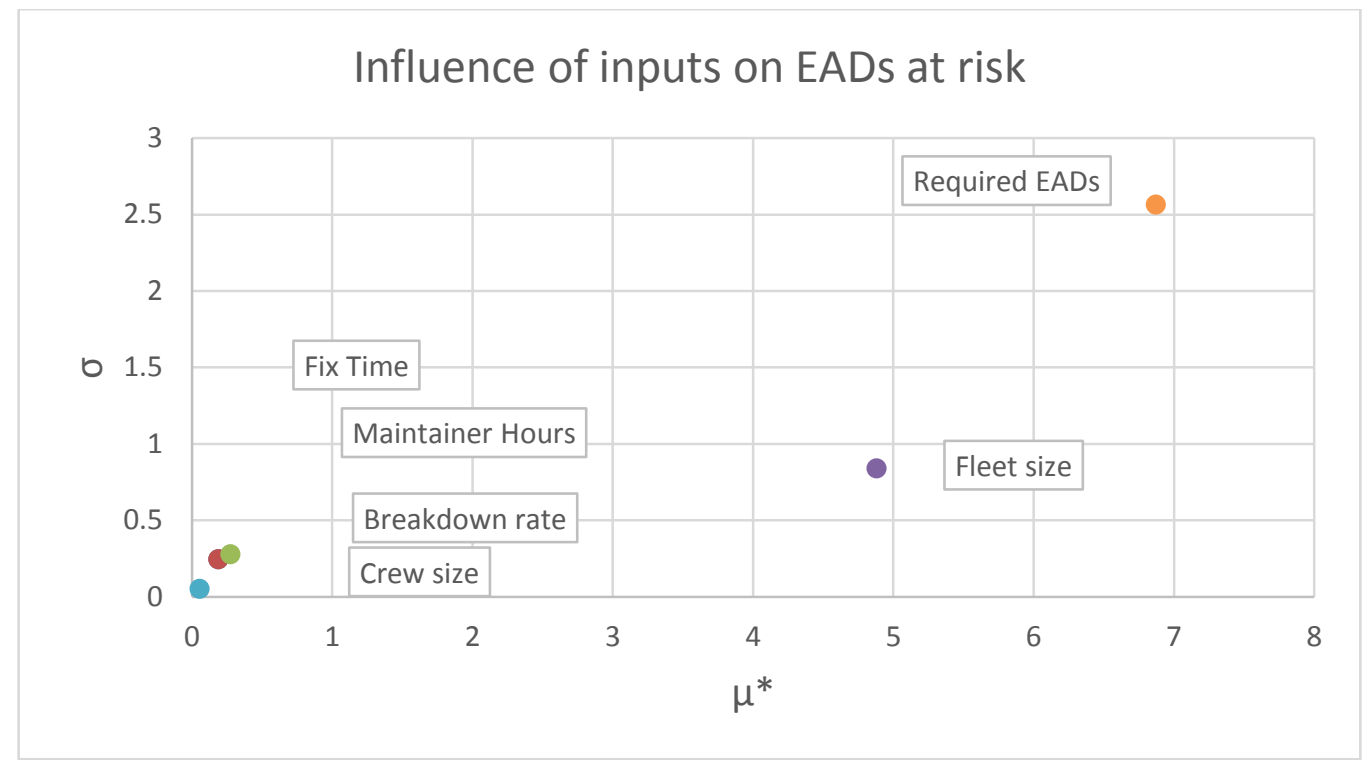

Figure 18. Plot of the two sensitivity measures for each input affecting the risk. 
Note that the crew size, fleet size and required EADs are not inputs in the strict sense. The crew size is estimated as the number of people needed in the average maintenance of an ET. The fleet size and required EADs are directly related (as explained before, the fleet size determines the maximum EADs) and the ratio of required EADs per ET is something that could be chosen.

It can be seen that the breakdown rate, fix time and crew size have a linear effect on the cost, as the value for $\mu^{*}$ is significant while the values for $\sigma$ are negligible. However, maintainer hours, crew size and required EADs have higher values for both sensitivity measures; therefore they have a higher effect on cost and present either a non-linear effect or interactions with other inputs. On the other hand, breakdown rate, fix time, maintainer hours and crew size have a negligible effect on the EADs at risk, as the values for $\mu^{*}$ and $\sigma$ are low. Conversely, fleet size and required EADs have a huge impact on risk (very high values for $\mu^{*}$ ), and again they present non-linear/interaction effects. In conclusion, the effects of the inputs on the result are summarised in Table 9.

Table 9: Summary of sensitivity analysis results

Input Effect on result

\begin{tabular}{|l|l}
\hline Breakdown rate, Fix time and Crew size & Linear and significant on cost
\end{tabular}

Fleet size and Required EADs $\quad$ Mutual interaction and dominant on both cost and risk

\begin{tabular}{l|l} 
Maintainer hours & Non-linear and dominant on cost
\end{tabular}

Even though the method does not make a distinction, fleet size and EADs at risk have an interaction effect as they both change the ratio of required EADs per ET, which ultimately determines the performance of the system. When setting the requirements for a mission, the choice of the required days per ET will establish a "demanding" strategy (with high cost but low risk) or a "redundancy" strategy (with low cost but high risk). For reference, the lever profiles for the Land vehicle case study for two different required EADs per ET are shown in Figure 19. 


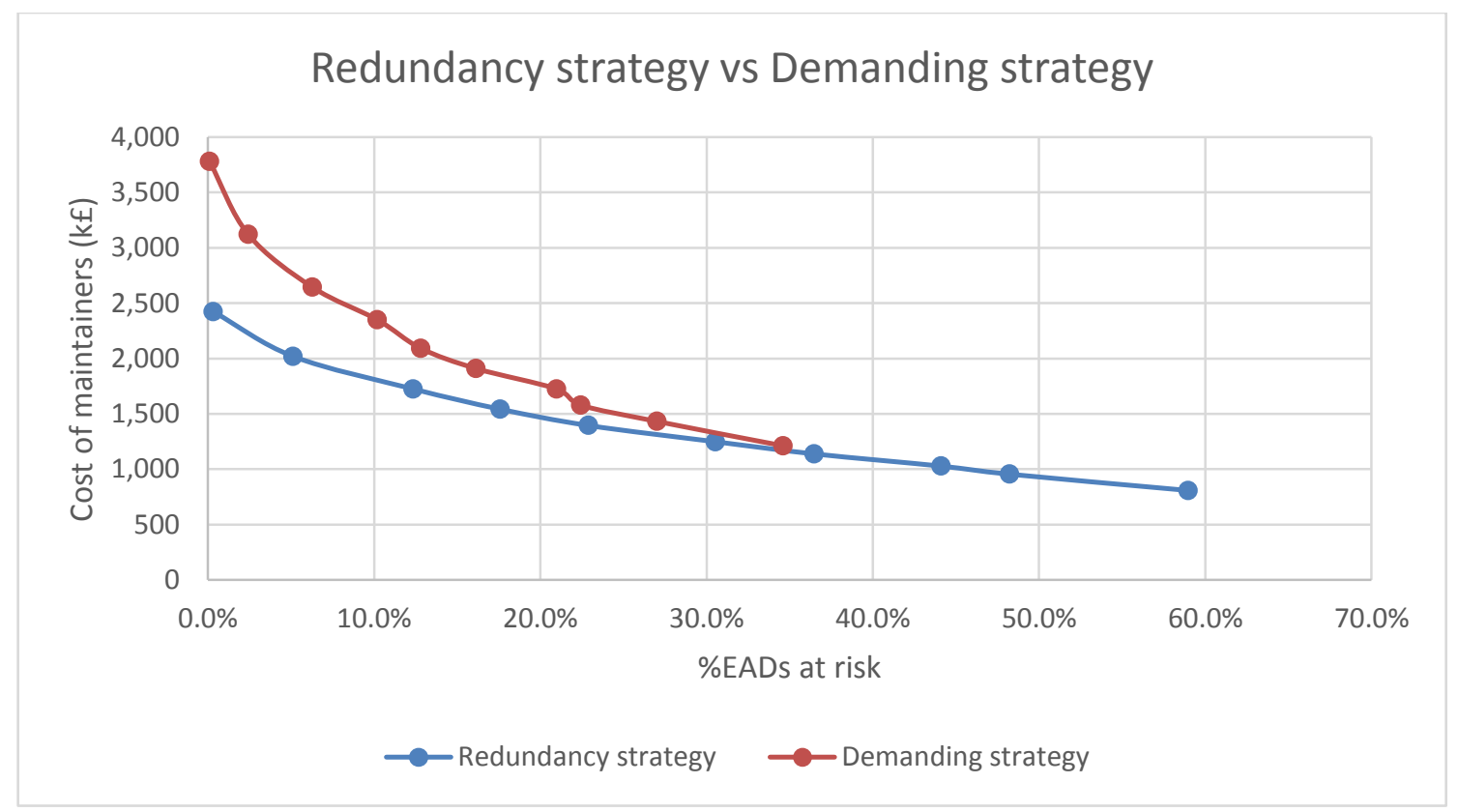

Figure 19. Lever profiles for two strategies to meet the same target availability

\section{Conclusions and Future work}

\subsection{Conclusions}

This article presented an approach focusing on building a process for understanding the trade-offs within CM activities at the ET level. The approach integrates existing practices by considering the "Spares Lever" review. Typically, whenever sources of inaccuracies are identified, the practical implementation of proposed solutions would encounter physical limitations (such as coding, tagging or inventory software). Revising the "Queuing Levers" had led to the implementation of a different queuing theory model (involving a finite source based approach) which is more suitable for maintenance activities (i.e. it represents the practical implementation more accurately). The main benefit is a better prediction of the maintenance system performance and therefore an enhanced cost and availability estimation becomes available.

Similar notions have previously been promoted in past research where finite queuing models have led to cost savings. It also influences availability predictions, as it estimates the optimum resources required to achieve a target. This could eventually indicate whether the required availability is met. Therefore, it was interesting to compare the results of the finite model with the availability results obtained in real life to assess its applicability. The revision of the queuing models also validates basic assumptions, such as the statistical behaviour of the inputs. Combined with the finite source model, it is found that the failure rate distribution does not affect the system (i.e. only the mean value has an effect). In addition, real data indicates that "fix time" distributions tend to be exponential, as assumed by the queuing model. Nevertheless, the data maturity levels of many ETs have prompted to work with three point estimates, which still presents a source of inaccuracy. Thus, the tendency should be towards working with more reliable data histograms to obtain more precise inputs and to avoid overestimating the result at high confidence levels. The main limitation on the inputs is imposed by the mean based solution of the queuing model. Having an analytical solution in queuing theory limits the assumptions for the inputs. Therefore, the overall 
approach has been to assess whether the real data could approximate the assumptions, rather than building a model applicable to the real data. Arguably, this is to find a balance between the modelling effort and the accuracy of its solution.

Finally, the sensitivity analysis has shown that the duplet fleet size and required EADs exhibits the most important influence on the "Queuing Levers" result, affecting both cost and availability at risk. They both work together as the ratio "required EADs per ET" which determines how demanded the maintenance system is going to be for certain conditions (e.g. failure rate and fix time). Nonetheless, it has to be taken into account that changing the required EADS per ET could indicate that the levels of utilisation of the equipment also change. That is to say, the failure rate or even fix time could be altered, which could lead to significant changes in the cost and availability predictions. The authors would like to highlight that even though the developed methodology has been implemented within the military context, it can be adapted across other industries such as commercial airlines or railways. The approach is not expected to require any modifications, but it will require validation.

\subsection{Future Work}

Following up from this research work, the authors are investigating the use of combi-levers that aggregates individual results of the levers. Hence, the combination of the different resources required is done in a parallel way. Since maintenance is a serial process (e.g. diagnose, repair and test), current efforts are being focused on investigating interactions in between the different resources (e.g. people, facilities). In the current approach, a delay caused by a spare part during rectification does not influence the overall system; it is an isolated delay. However, the delay due to that spare would affect the queues upstream, and the overall impact in availability could be significantly longer. Figure 20 shows the possible network based queuing model within the finite population context.

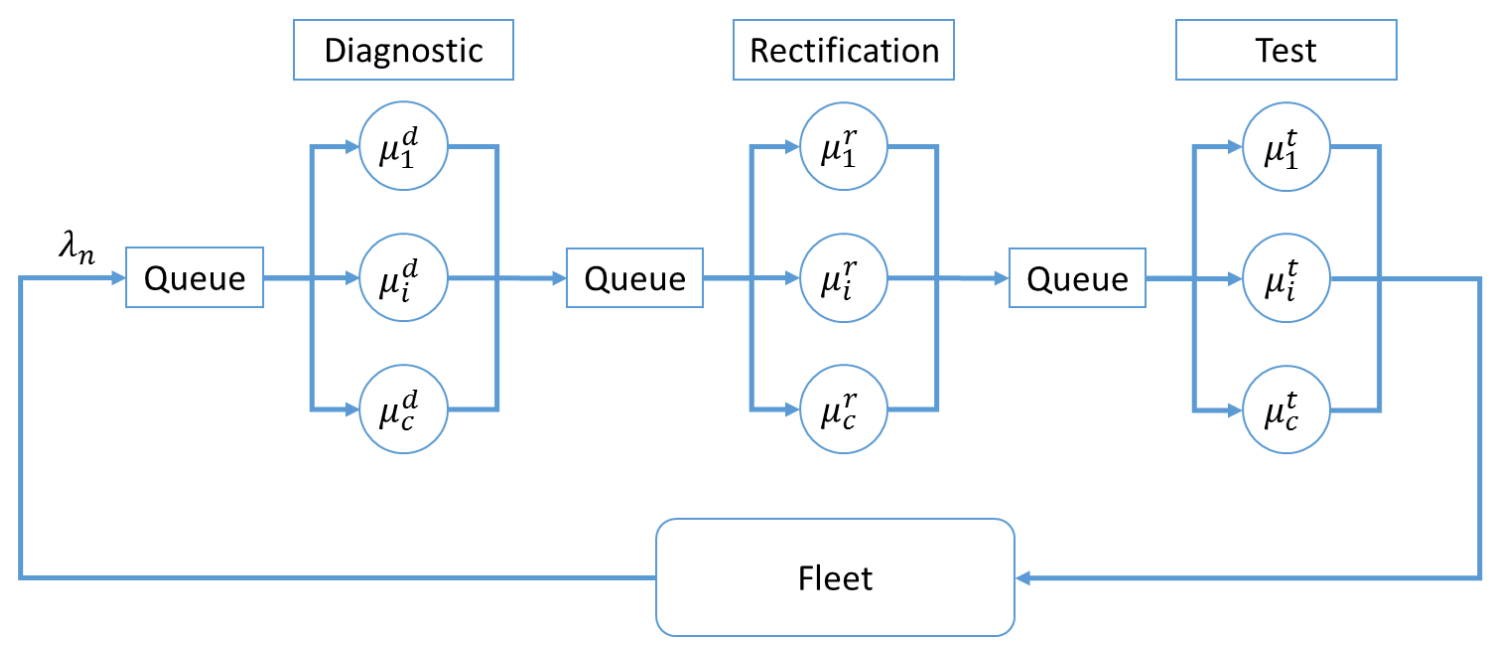

Figure 20. Possible network based queuing model with finite population

In addition, each point in the lever profiles represents the cost of meeting the required EADs at a certain confidence level; and the corresponding \%EADs at risk. Each of these points are the result of virtually increasing the inputs (according to the confidence levels set by the three point estimates) to build safety stocks of the resource, such as maintainers. In most cases, the increase in the inputs produces a steep response in the system, more accentuated 
at the higher confidence levels. That means, achieving the same requirement (EADs) is more and more difficult at each confidence level. This approach ensures being on the safe side, but it can also indicate a substantial cost overestimate.

Conversely, the study of building safety stocks could be done just at the $50 \%$ confidence level, which represents the inputs real mean values. However, this approach can underestimate the needed resources in case the real conditions are worse than expected (e.g. the failures are more frequent or repairs take longer than predicted). An approach that could find a less overrated cost estimate and avoid the risk of just using the $50 \% \mathrm{CL}$ is the use of real data histograms. This indicates that the three point estimates have a tendency to distort the values for the inputs at the different confidence levels; but using the real histogram could provide a more accurate result. This will depend on an increase in the data maturity levels. Thus, future work will also concentrate on modelling the safety stock requirements for $\mathrm{CM}$.

\section{Acknowledgements}

The authors would like to express their gratitude to the Ministry of Defence UK and more specifically the Equipment Support Continuous Improvement Team for sponsoring the project. Additionally, the authors acknowledge the support provided by members of the Through-life Engineering Services Centre at Cranfield University. The authors would also like to thank the reviewers for the constructive comments on the paper.

\section{References}

Ahn S, Kim W, (2011) On determination of the preventive maintenance interval guaranteeing system availability under a periodic maintenance policy. Structure and Infrastructure Engineering, 7(4): 307-314.

Ayeni P, Ball P, Baines T. (2016) Towards the strategic adoption of Lean in Aviation Maintenance Repair and Overhaul (MRO) industry: an empirical study into the industry's Lean status. Journal of Manufacturing Technology Management, 27(1): 3861.

Baines TS, Lightfoot HW, Benedettini O, Kay J. M. (2009) The servitization of manufacturing: A review of literature and reflection on future challenges. Journal of Manufacturing Technology Management, 20(5): 547-567.

Baines, T., \& Lightfoot, H. (2014) Servitization in the Aircraft Industry: Understanding Advanced Services and the Implications of Their Delivery. In Servitization in Industry (pp. 45-54). Springer International Publishing.

Bano M, Zowghi, D. (2015) A systematic review on the relationship between user involvement and system success. Information and Software Technology, 58: 148-169.

Bender A, Pincombe A. and Sherman G. (2009a) Determining some of the triggers for early life cycle failure in decay affected logistic queueing simulation. ANZIAM Journal, 51: 715-729.

Bender A, Pincombe AH, Sherman GD. (2009b), Effects of decay uncertainty in the prediction of life-cycle costing for large scale military capability projects, 18th World IMACS 
Congress and MODSIMO9 International Congress on Modelling and Simulation: Interfacing Modelling and Simulation with Mathematical and Computational Sciences, Proceedings, pp. 1573.

Campolongo F, Cariboni J, Saltelli A. (2007) An effective screening design for sensitivity analysis of large models, Environmental Modelling and Software, 22(10): 1509-1518.

Chandola V, Banerjee A, Kumar V. (2009) Anomaly detection: A survey. ACM computing surveys (CSUR), 41(3): 1-72.

Checkland, P. B. (1989). Soft systems methodology. Human systems management, 8(4), $273-$ 289.

Das Adhikary, D., Bose, G. K., Jana, D. K., Bose, D., \& Mitra, S. (2016). Availability and costcentered preventive maintenance scheduling of continuous operating series systems using multi-objective genetic algorithm: A case study. Quality Engineering, 28, 352-357.

Datta PP, Roy R. (2010) Cost modelling techniques for availability type service support contracts: A literature review and empirical study. CIRP Journal of Manufacturing Science and Technology, 3(2): 142-157.

de Jonge B, Klingenberg W, Teunter R, Tinga T. (2016) Reducing costs by clustering maintenance activities for multiple critical units. Reliability engineering \& system safety, 145: 93-103.

Eiroa AL. (2014) Trade - off analysis between Preventive and Corrective Maintenance, Cranfield University, UK.

Erkoyuncu JA, Khan SHS, Roy R. (2016) A framework to estimate the cost of No-Fault Found events. International Journal of Production Economics, 173: 207-222.

Erkoyuncu JA, Roy R, Shehab E, Kutsch E. (2014) An innovative uncertainty management framework to support contracting for product-service availability. Journal of Service Management, 25(5): 603-638.

Faccio M, Persona, A, Sgarbossa, F, Zanin G. (2014) Industrial maintenance policy development: A quantitative framework. International Journal of Production Economics, 147: 85-93.

Ghodrati, B. (2005) "Reliability and operating environment based spare parts planning", Lulea, University of Technology, Diss.

Ghodrati B, Banjevic D. Jardine AKS. (2010) Developing effective spare parts estimations results in improved system availability, Proceedings - Annual Reliability and Maintainability Symposium.

Gross D, Harris, CM. (1985) Finite-Source Queues, Fundamentals of queueing theory, 2nd ed., Wiley, New York, pp. 104-108.

Hagmark P, Virtanen S. (2007) Simulation and calculation of reliability performance and maintenance costs, pp. 34 . 
Hastings NAJ. (2015) Management of In-Service Assets. In Physical Asset Management (pp. 187-205). Springer International Publishing.

Keeffe T, Ormsby, G. (2015) A logistics support framework: a systems-based approach to logistics planning for development projects. Development in Practice, 25(6): 843-855.

Khan S. (2015) Maintenance Requirements in Aerospace Systems. Procedia CIRP, 38: 100105.

Khan S, Phillips P, Jennions I, Hockley C. (2014a) No Fault Found events in maintenance engineering Part 1: Current trends, implications and organizational practices. Reliability Engineering \& System Safety, 123: 183-195.

Khan S, Phillips P, Jennions I, Hockley C. (2014b) No Fault Found events in maintenance engineering Part 1: Current trends, implications and organizational practices. Reliability Engineering \& System Safety, 123: 183-195.

Khan S, Phillips P, Hockley C, Jennions I. (2015) No fault found: the search for the root cause, SAE International, Product Code of R-441, ISBN of 978-0-7680-8122-0

Kumar U, Galar D, Parida A, Stenström C, Berges L. (2013) Maintenance performance metrics: a state-of-the-art review. Journal of Quality in Maintenance Engineering, 19(3): 233-277.

Madu CN, Kuei C, Chen J. (1995) A decision support systems approach to adjust maintenance float system availability levels, Computers and Industrial Engineering, 28(4): 773-786.

Martin JD, Finke DA, Ligetti CB. (2011) On the estimation of operations and maintenance costs for defense systems, pp. 2478.

Monnin M, Lung B, and Sénéchal O. (2007) A methodology for weapon system availability assessment, incorporating failure, damage and regeneration, IFAC Proceedings Volumes (IFAC-PapersOnline), 40(6): 157-162.

Morris MD. (1991) Factorial sampling plans for preliminary computational experiments. Technometrics, 33(2): 161-174.

NATO ARMP-4 (1996) Guidance for writing NATO R \& M requirements documents" ARMP-4 (edition 2), 2-5.

Orsagh RF, Allen EC, Schoeller M. Roemer MJ. (2003) A mission-based logistics and maintenance support cost simulation environment. IEEE Aerospace Conference Proceedings, 8: 1164-1169.

Peito F, Pereira G, Leitão A, Dias L, and Oliveira JA. (2013) A flexible decision support tool for maintenance float systems - A simulation approach, 12th International Conference on Modeling and Applied Simulation, MAS 2013, Held at the International Multidisciplinary Modeling and Simulation Multiconference, I3M 2013, pp. 29. 
Phillips P, Diston D, Starr A. (2011) Perspectives on the commercial development of landing gear health monitoring systems. Transportation research part $C$ : emerging technologies, 19(6): 1339-1352.

Qu M, Yu S, Chen D, Chu J, Tian B. (2016) State-of-the-art of design, evaluation, and operation methodologies in product service systems. Computers in Industry, 77: 1-14.

Rahman A. and Chattopadhyay G. (2008) Cost estimation for Maintenance contracts for complex asset/equipment, IEEE International Conference on Industrial Engineering and Engineering Management, DOI: 10.1109/IEEM.2008.4738091, pp. 1355-1358.

Roy R, Tiwari A, Tracht K, Shehab E. Mehnen J. (2015) Proceedings of the 4th International Conference on Through-life Engineering Services (Edited). Procedia CIRP Volume 38, Pages 1-288.

Roy R, Shaw A, Erkoyuncu JA, Redding L. (2013) Through-life engineering service Measurement and Control, 46 (6): 172-175.

Sheikh AK, Younas M, Raouf A. (2000) Reliability based spare parts forecasting and procurement strategies. Maintenance, Modeling and Optimization, Springer, pp. 81110.

Sherman GD, Owen KR, Pincombe AH, Bender A. (2011) Uncertainty in availability generated by inventory management controls in a generic repairable item sustainment system, ANZIAM Journal, 53: C539-C560.

Simeu-Abazi Z, Di Mascolo M, Gascard E. (2014) Queuing network-based methodology for designing and assessing performance of centralized maintenance workshops. Journal of Manufacturing Technology Management, 25(4): 510-527.

Thomas AJ, Mason-Jones R, Davies A, John EG. (2015) Reducing turn-round variability through the application of Six Sigma in aerospace MRO facilities. Journal of Manufacturing Technology Management, 26(3): 314-332.

Upadhya KS, Srinivasan NK. (2003) Availability of weapon systems with multiple failures and logistic delays. International Journal of Quality and Reliability Management, 20(7): 836846.

Upadhya KS, Srinivasan NK. (2005) System simulation for availability of weapon systems under various missions. Systems Engineering, 8(4): 309-322.

Upadhya KS, Srinivasan NK, (2012) Availability estimation using simulation for military systems, International Journal of Quality and Reliability Management, 29(8): 937-952.

Yumakogullari Ö, Aydemir R, Guloglu B. (2015) Global and Regional Air Traffic, Fleet and MRO Outlook in Air Transportation. Siyaset, Ekonomi ve Yönetim Araştırmaları Dergisi, 3(4): 161-166.

Zhou X, Li Y, Xi L, Lee J. (2015) Multi-phase preventive maintenance policy for leased equipment. International Journal of Production Research, 53(15): 4528-4537. 
2017-05-29

Perspectives on trading cost and availability for corrective maintenance at the equipment type level

\section{Erkoyuncu, John Ahmet}

Elsevier

John Ahmet Erkoyuncu, Samir Khan, Alexandre López Eiroa, Nigel Butler, Keith Rushton, Simon Brocklebank, Perspectives on trading cost and availability for corrective maintenance at the equipment type level, Reliability Engineering \& System Safety, Volume 168, December 2017, Pages 53-69

http://dx.doi.org/10.1016/j.ress.2017.05.041

Downloaded from Cranfield Library Services E-Repository 